WSRC-TR-2003-00166

KEYWORDS:

Sludge Suspension

Computational Approach

Sludge Mixing

Jet Flow Model

Mixing Pump Model

RETENTION - Permanent

\title{
EVALUATION OF SLUDGE REMOVAL CAPABILITIES FOR ADMP MIXER IN TANK 18
}

SAVANNAH RIVER TECHNOLOGY CENTER

Si Young Lee

April 2003

Westinghouse Savannah River Company

Savannah River Site

Aiken, SC 29808

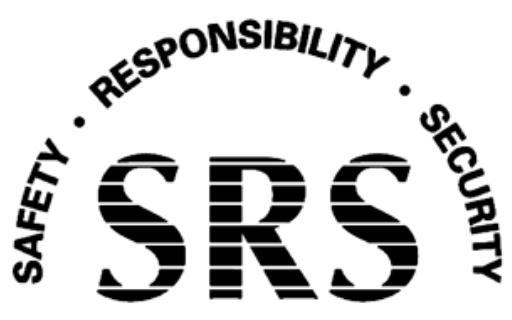

Prepared for the U.S. Department of Energy under Contract No. DE-AC09-96SR18500 
This document was prepared in conjunction with work accomplished under Contract No. DE-AC09-96SR18500 with the U. S. Department of Energy.

\section{DISCLAIMER}

This report was prepared as an account of work sponsored by an agency of the United States Government. Neither the United States Government nor any agency thereof, nor any of their employees, makes any warranty, express or implied, or assumes any legal liability or responsibility for the accuracy, completeness, or usefulness of any information, apparatus, product or process disclosed, or represents that its use would not infringe privately owned rights. Reference herein to any specific commercial product, process or service by trade name, trademark, manufacturer, or otherwise does not necessarily constitute or imply its endorsement, recommendation, or favoring by the United States Government or any agency thereof. The views and opinions of authors expressed herein do not necessarily state or reflect those of the United States Government or any agency thereof.

This report has been reproduced directly from the best available copy.

Available for sale to the public, in paper, from: U.S. Department of Commerce, National Technical Information Service, 5285 Port Royal Road, Springfield, VA 22161, phone: (800) 553-6847, fax: (703) 605-6900

email: orders@ntis.fedworld.gov

online ordering: http://www.ntis.gov/help/index.asp

Available electronically at http://www.osti.gov/bridge

Available for a processing fee to U.S. Department of Energy and its contractors, in paper, from: U.S. Department of Energy, Office of Scientific and Technical Information, P.O. Box 62, Oak Ridge, TN 37831-0062,

phone: (865)576-8401,

fax: (865)576-5728

email: $\underline{\text { reports@ adonis.osti.gov }}$ 


\section{Nomenclature}

$A=\operatorname{area}\left(\mathrm{ft}^{2}\right.$ or $\left.\mathrm{m}^{2}\right)$

$\mathrm{d}=$ nozzle or particle diameter (ft or $\mathrm{m}$ )

$\mathrm{D}=$ tank diameter ( $\mathrm{ft}$ or $\mathrm{m}$ )

$\mathrm{C}=$ constant or interpolation factor (--)

$\mathrm{F}=$ Force $(\mathrm{N})$

$\mathrm{g}=$ gravity $\left(\mathrm{m} / \mathrm{sec}^{2}\right)$

$\mathrm{h}=$ liquid height above the nozzle (inch)

$\mathrm{H}=$ total tank level (inch)

$\mathrm{I}=$ turbulence intensity $(--)$

$\mathrm{k}=$ turbulent kinetic energy $\left(=\frac{1}{2}\left(u^{\prime 2}+v^{\prime 2}+w^{\prime 2}\right)_{\text {avg }}\right)$

$\mathrm{P}=$ pressure $(\mathrm{Pa})$

$\operatorname{Pr}=$ Prandtl number, $\mu \mathrm{C}_{\mathrm{p}} / \mathrm{k},(--)$

$r=$ radial distance from the center of tank center ( $f t$ or $m$ )

$\mathrm{R}=$ tank radius ( $\mathrm{ft}$ or $\mathrm{m}$ )

$\operatorname{Re}=$ Reynolds number, $\mathrm{d} \rho \mathrm{u} / \mu$

SG or sg = specific gravity

$\mathrm{t}=$ time (second)

$\mathrm{U}=$ nozzle exit velocity ( $\mathrm{ft} / \mathrm{sec}$ or $\mathrm{m} / \mathrm{sec}$ )

$\mathrm{u}=$ component velocity in $\mathrm{x}$-direction $(\mathrm{ft} / \mathrm{sec}$ or $\mathrm{m} / \mathrm{sec}$ )

$\mathrm{u}^{\prime}=$ local turbulent velocity fluctuation in $\mathrm{x}$-direction ( $\mathrm{ft} / \mathrm{sec}$ or $\mathrm{m} / \mathrm{sec}$ )

$\mathrm{v}=$ local flow velocity or component velocity in $\mathrm{y}$-direction (ft/sec or $\mathrm{m} / \mathrm{sec}$ )

$v^{\prime}=$ local turbulent velocity fluctuation in y-direction (ft/sec or $\mathrm{m} / \mathrm{sec}$ )

$\mathrm{V}=$ average velocity magnitude (ft/sec or $\mathrm{m} / \mathrm{sec}$ )

$\mathrm{w}=$ component velocity in z-direction ( $\mathrm{ft} / \mathrm{sec}$ or $\mathrm{m} / \mathrm{sec}$ )

$\mathrm{w}^{\prime}=$ local turbulent velocity fluctuation in z-direction ( $\mathrm{ft} / \mathrm{sec}$ or $\mathrm{m} / \mathrm{sec}$ )

$\mathrm{x}=$ local position along the $\mathrm{x}$-direction under Cartesian coordinate system ( $\mathrm{ft}$ or $\mathrm{m}$ )

$y=$ local position along the $y$-direction under Cartesian coordinate system ( $\mathrm{ft}$ or $\mathrm{m}$ )

$\mathrm{z}=$ local position along the $\mathrm{y}$-direction under Cartesian coordinate system ( $\mathrm{ft}$ or $\mathrm{m}$ ) 


\section{WSRC-TR-2003-00166}

\section{$\underline{\text { Greek }}$}

$\rho=\operatorname{density~}\left(\mathrm{kg} / \mathrm{m}^{3}\right)$

$\varepsilon=$ rate of dissipation of turbulent kinetic energy

$\nabla=$ gradient operator

$\Omega=$ vorticity

$\psi=$ solid weight per weight of liquid

$\mu=$ dynamic viscosity $\left(\mathrm{N} \mathrm{sec} / \mathrm{m}^{2}\right)$

$v=$ kinematic viscosity $\left(\mathrm{m}^{2} / \mathrm{sec}\right)$

$\eta=$ non-dimensional distance (--)

$\phi=$ ratio of local velocity to velocity at nozzle exit (--)

\section{Subscript}

avg $=$ average

$f=$ fluid

fo $=$ clear fluid

fs = suspended fluid

$\mathrm{L}=$ lifting

$\mathrm{m}=$ maximum

$0=$ jet nozzle exit

$\mathrm{p}=$ particle

$\mathrm{s}=$ static

$\mathrm{t}=$ turbulent flow

$\mathrm{v}=$ flow velocity or vertical

$\mu=$ viscosity 


\section{Abstract}

In support of sludge suspension and removal operations in Tank 18, flow evolution models were developed and performance calculations completed for the advanced design mixer pump (ADMP). The ADMP was modeled as a hydraulic jet for the sludge mixing operation of Tank 18, which was submerged at the center of the tank. The modeling calculations were based on prototypic tank geometry and expected nominal operating conditions as defined by High-Level Waste (HLW) Engineering.

Computational Fluid Dynamics (CFD) approach was taken to simulate the Tank 18 operations with and without cohesive sludge mound using the FLUENT ${ }^{\mathrm{TM}}$ code. The models employed a three-dimensional approach with a two-equation turbulence model since this modeling approach was verified by both TNX test data and literature data in the previous work. In the analysis, local velocity magnitude was used as a measure of slurrying and suspension capability.

The modeling results show that normal operations in Tank 18 with the existing ADMP mixer and a 65 inch liquid level provide adequate sludge removal in most regions of the tank. The exception is the region within about $1 \mathrm{ft}$ of the wall, assuming the minimum velocity required to suspend waste sludge is $2.27 \mathrm{ft} / \mathrm{sec}$. In this case, if sludge particles are free and smaller than about 10 microns in diameter, fluid velocities near the wall region are high enough to keep them suspended.

Sensitivity results show that higher tank level and lower elevation of pump nozzle would result in better performance in suspending and removing the sludge. The results also show that about 2 days' ADMP operation for an indexed pump orientation is required to remove the sludge mound based on the ADMP jet spread angle computed by the Tank 18 CFD simulation models and the sludge cleaning rates observed by operations of the Tank 16 slurry pump. Computational results for two different fluids, water and a typical slurry, show that the maximum clearing distance is not sensitive to the slurry fluid properties. 
Report: WSRC-TR-2003-00166

Date: $\quad$ 10/29/2003

18

Page:
WESTINGHOUSE SAVANNAH RIVER COMPANY

EVALUATION OF SLUDGE REMOVAL CAPABILITIES FOR ADMP MIXER IN TANK

(This Page Intentionally Left Blank) 


\section{Introduction}

Tank 18 is a 1.3 million-gallon capacity, single-wall, type IV waste tank located in the FTank Farm area. The tank was placed into service as a receiver of low heat waste. The tank is an $85 \mathrm{ft}$ diameter flat-bottomed cylindrical carbon steel tank with a height of about $34 \mathrm{ft}$. There are no cooling coils or internal supports inside the tank. The waste in the tank consists of salt and sludge. The salt has been removed by dissolution in water and transferred to other tanks for storage. The remaining sludge will then be hydraulically resuspended and transferred to other tanks.

To suspend the settled sludge, water will be added to Tank 18 as a slurry medium, and the Advanced Design Mixer Pump (ADMP) will be used to suspend the sludge. The ADMP has a bottom suction with two opposing discharge nozzles [Refs. 1, 2]. The pump suction and nozzle diameters are 17.38 in and 6 in, respectively. The pump is immersed in the sludge layer, allowing a recirculating mixture of sludge and water to serve as the feed flow. The pump is located in the center riser of Tank 18. The cleaning pattern generated on the tank bottom defines the effective cleaning radius (ECR) when the pump rotates. A Maximum Cleaning Distance (MCD) can be defined when the pump is stationary. The ECR or MCD has been one of the measures or indicators of the cleaning ability of a mixing pump. After the ADMP suspends the sludge, waste transfers from Tank 18 to another tank will be performed. Detailed design information for the ADMP pump is shown in Table 1.

As shown in Fig. 1, the tank is $85 \mathrm{ft}$ in diameter and $34 \mathrm{ft}$ high. Under waste removal operating conditions, the tank level is maintained at about 65 in. The existing ADMP mixer placed at the center of the tank was used to suspend or transport sludge deposited in the tank. It is a recirculating, centrifugal pump with a top mounted $300 \mathrm{hp}$ motor. Its long shaft is enclosed in a 16" nominal pipe diameter casing. It is located $42.5 \mathrm{ft}$ from the tank wall and 23 in above the tank bottom as one of the nominal operating conditions.

The primary objective of the present work is to model Tank 18 with the existing ADMP mixer for various pump elevations and tank liquid levels when the mixer is submerged at the center of the tank. The computational models will be used to estimate the cleaning capabilities of the ADMP for sludge removal and to evaluate flow evolutions of waste slurry under various operating conditions in Tank 18. The basic CFD model for the Tank 18 system was developed and benchmarked against the TNX test data and literature data in the previous work [Ref. 2]. A schematic diagram for the Tank 18 system used in the analysis is illustrated in Fig. 1. Typical flow developments and evolutions of a jet flow discharged from a submerged mixer are shown in Fig. 2.

The analysis results will be used to evaluate hydraulic cleaning operations for waste removal. This information will also assist in the operating plan for Tank 18 waste removal and in identifying special requirements for sampling and monitoring the sludge suspension. 
Report: WSRC-TR-2003-00166

Date: $\quad 10 / 29 / 2003$

18

Page: $\quad 4$ of 48

Table 1. Specifications of slurry pumps used for the present analysis.

\begin{tabular}{|c|c|}
\hline Design Parameters & ADMP \\
\hline Horsepower, hp & 300 \\
\hline Casing diameter, inches & 39.0 \\
\hline $\begin{array}{c}\text { Number of discharge nozzles } \\
\text { (flow directions) }\end{array}$ & 2 \\
\hline Nozzle diameter, inches & 6.0 \\
\hline $\begin{array}{c}\text { Number of pump suctions } \\
\text { (suction locations) }\end{array}$ & 1 \\
\hline Pump speed (rpm) & (bottom of pump) \\
\hline Suction diameter, inches & 1185 to 900 \\
\hline Flowrate per nozzle, gpm & 17.38 \\
\hline Flow velocity at pump discharge, ft/sec & 5200 at $1185 \mathrm{rpm}$ \\
\hline
\end{tabular}

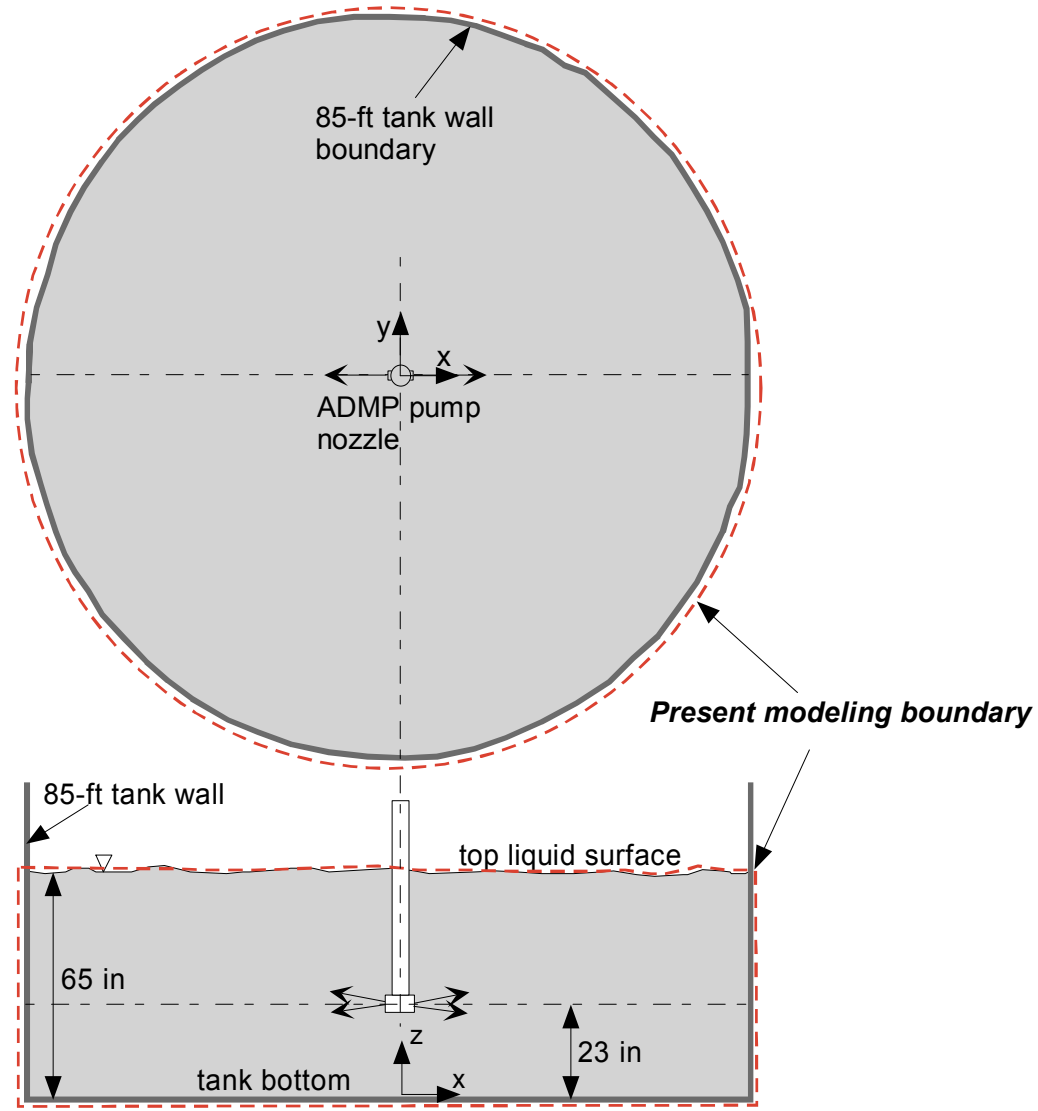

Figure 1. Schematic of Tank 18 operation system showing the present modeling boundary 


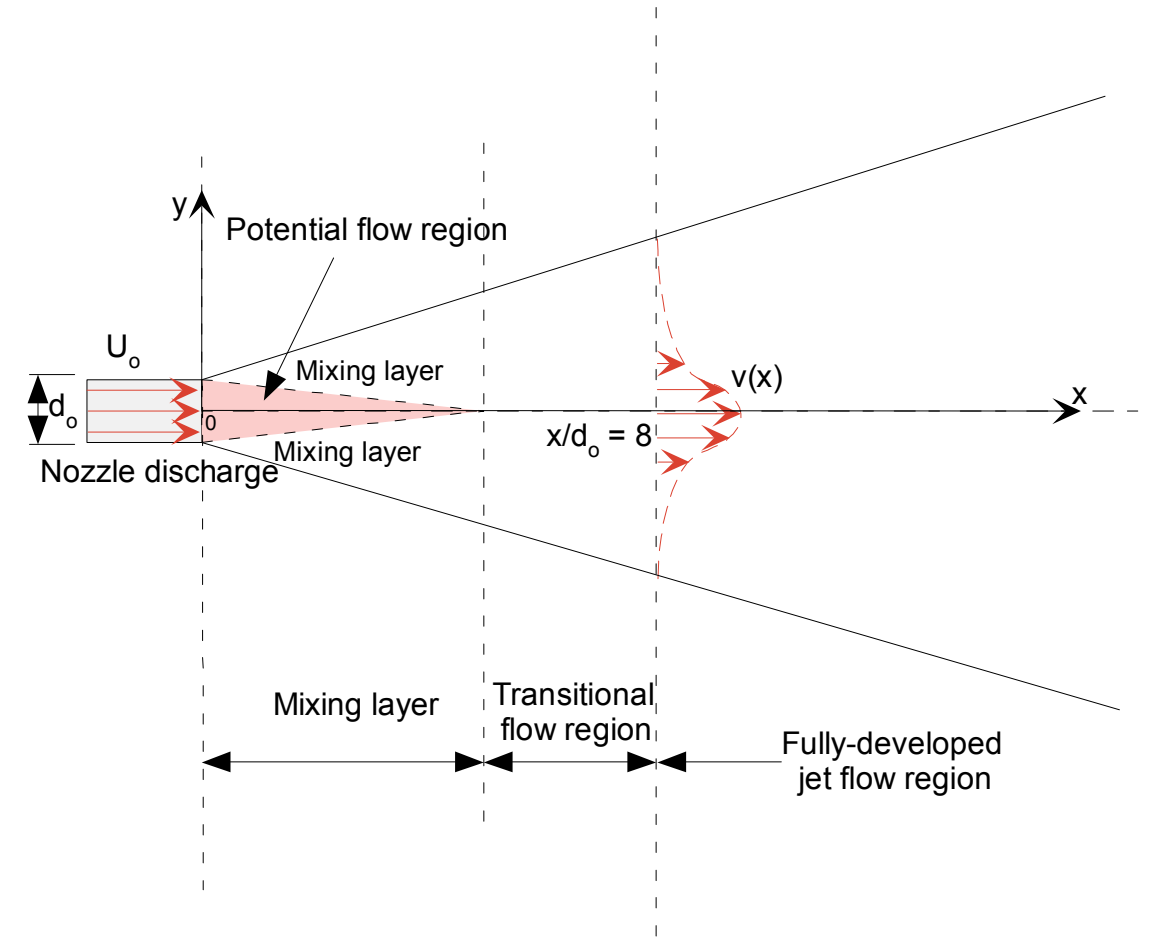

Figure 2. Flow developments and evolutions of a typical submerged jet mixer along the discharge direction

\section{Solution Methodology}

The present work is mainly concerned with the suspension of sludge particles induced by the ADMP mixer, which will be investigated by a computational modeling approach. Prior to discussion of the modeling approach for the mixer flow bounded in a finite space such as Tank 18 container, the literature results for a free turbulent jet flow are reviewed briefly since the free jet flow has an important physics of turbulent flow least dependent on effects of fluid properties and geometrical boundary conditions, and it is similar to the basic flow patterns of the bounded wall jet. The previous work [Ref. 2] and the literature data [Refs. 9, 10] show that when a turbulent jet of fluid is discharged from a nozzle with a diameter $d_{0}$, it both entrains fluids and expands as shown in Fig. 2. Most mixing action and entrainment takes place in the region of fully-developed flow which begins at a distance of approximately eight nozzle diameters as indicated in Fig. 2. In the literature [Ref. 9], the non-dimensional velocity distribution $\varphi_{v}$ along the jet axis of this region for a homogeneous fluid jet is given by

$$
\varphi_{v}=\left(\frac{v(x)}{U_{o}}\right)=C_{o}\left[\frac{x}{d_{o}}\right]^{-1}=C_{o} \eta^{-1}
$$

In eq. (1), $C_{0}$ is a constant determined by the turbulence characteristics of the jet, $U_{0}$ the nozzle exit velocity, $v(x)$ the local velocity at a point $x$, and $x$ the distance from nozzle. 
Page: $\quad 6$ of 48

Abramovich (1963) correlated the experimental data for a free turbulent jet submerged in fluid, using the non-dimensional form provided by eq. (1). From his work, the proportional constant $C_{o}$ in eq. (1) was determined to be 6.32 .

Equation (1) shows that the velocity at any point in the region of established flow is directly proportional to the product, $d_{0} V_{o}$. Thus, the one-dimensional entraining distance corresponding to minimum entrainment velocity can be estimated theoretically when nozzle size and pumping flowrate are provided.

However, the fluid domain for the present work has both a solid boundary and a free surface boundary as the jet expands into the downstream region and then the flow recirculates via the bottom suction within the tank. The spreading fluid is retarded by the frictional resistance of the wall, and the inner part of the flow may be expected to show a certain structural similarity to a boundary layer, whereas entrainment of quiescent fluid occurs near the outer edge of the flow which accordingly is likely to resemble a free jet in character as illustrated in Fig. 2.

When a solid structure or wall surface is present near the jet nozzle, the jet flow will feel a three-dimensional interaction from the wall boundary and free surface. The literature results [Ref. 4] showed that the flow region of the jet up to 40 nozzle diameters, $\eta=40$ in eq. (1), was not affected by the presence or absence of a wall near the nozzle. The detailed discussions were provided in the previous work [Ref. 2].

The decay rate of the maximum discharge velocity and the evolution of flow patterns are potentially important phenomena affecting sludge suspension and mixing operations in Tank 18. They result from the interaction of a submerged turbulent jet with the tank wall and free surface. In the present work, flow velocity of the discharge jet is considered one of the key parameters governing the level of sludge suspension and turbulent mixing. The ability to shear the sludge layer known as scouring wall shear is also directly related to the local velocity.

The velocity required to suspend the sludge in SRS waste tanks has typically been based on the assumptions that solids in the sludge layer are loosely deposited [Ref. 2]. However, from the recent operation of the ADMP mixer [Ref. 8], it was found that two sludge mounds, estimated to be about 22 inches high, were observed at the corners of the tank when pump nozzle was placed 39 inches above the tank floor under 90 -in tank liquid level. The sludge mounds were observed to be more cohesive than assumed.

To understand the mechanism of particle lifting in the vicinity of a horizontal wall surface, one must determine minimum fluid velocity required to pick up, or erode solid deposition layer composed of particles of a particular size and density. In the present work, the pickup and erosion velocities for a solid particle lying on a horizontal wall surface are estimated by a force balance induced by a horizontal flow of fluid and the empirical correlation available in the literature. These velocities will be compared with the current velocity criterion for the sludge suspension $(2.27 \mathrm{ft} / \mathrm{sec})$, which was established by the previous work [Ref. 2]. 


\subsection{Establishment of Critical Scouring Criteria}

The initial movement of the solids deposited at the bottom of the tank identifies the critical condition or initial scour. It is usually described by two mechanistic criteria:

- The critical velocity criterion considers the impact of the liquid motion on the particle surface such as lifting force due to the gradient of the velocity around the particles.

- The critical shear stress criterion considers the frictional drag of the flow on the particles.

Information gained here will be employed in predicting critical conditions to initiate the movement of deposited solids. From these two criteria, the most conservative estimate will be chosen as a performance criterion for the operating guidance of the adequate solid mixing or suspension under the present geometrical configurations. The two criteria are developed below.

\section{Minimum Scouring Velocity}

The mechanism of particle lifting or pickup in the vicinity of a horizontal surface involves the fluid velocity required to pick up, or prevent deposition or settling of, particles of a particular size and density. The pickup or suspension velocity for a solid particle lying on a solid horizontal surface, as shown in Fig. 3, is evaluated from a balance of forces induced by or associated with a horizontal flow of fluid.

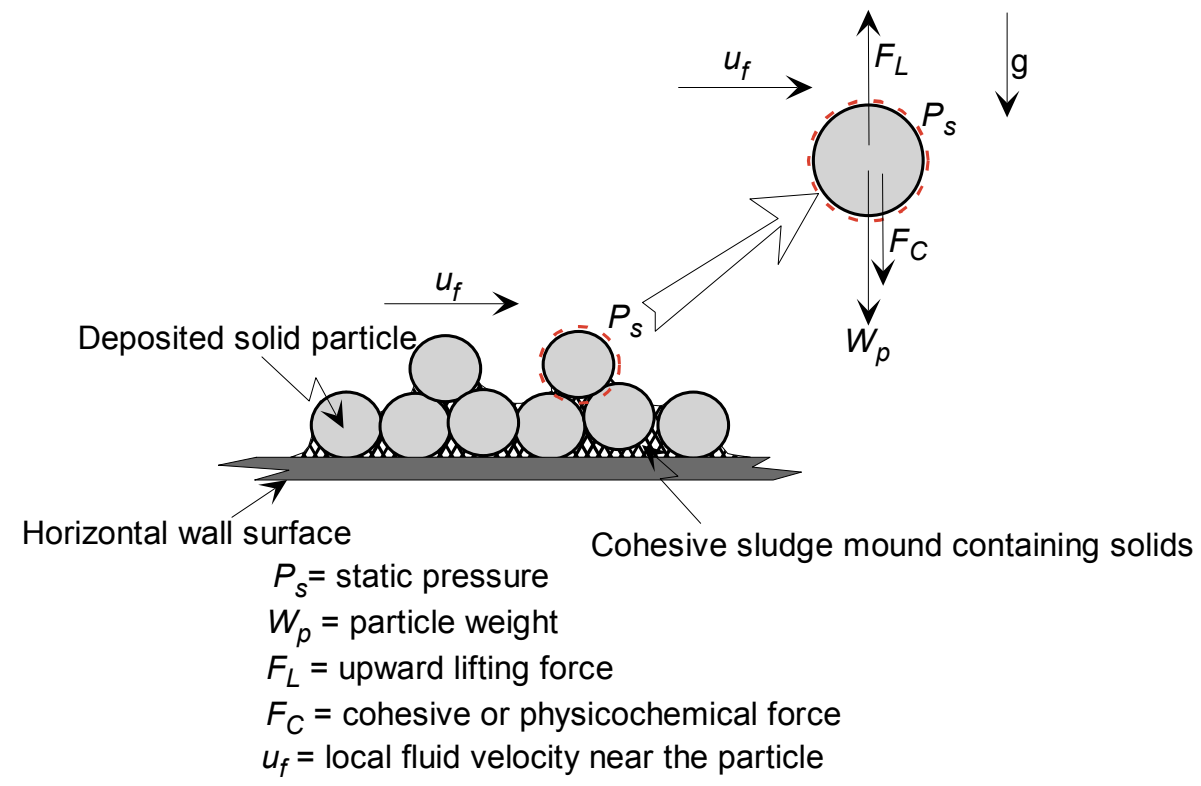

Figure 3. Static forces for a solid particle in a flowing fluid assuming a cohesive particle layer. 
18

Page: $\quad 8$ of 48

The condition of incipient movement for an assembly of cohesive solid particles is described in terms of the forces acting on the particle. The driving force for initial movement is the resultant force of the hydrodynamic lifting force, $F_{L}$, cohesive force between particles, $F_{C}$, and the submerged weight of particle, $W_{p}$, for a given hydrostatic pressure, $\mathrm{P}_{\mathrm{s}}$.

A particle such as shown in Fig. 2 is subject to an upward lifting force $F_{L}$, the Bernoulli force acting on the particle's projected area $\left(A_{p}\right)$ where

$$
F_{L}=\left(P_{s}+\frac{1}{2} \rho_{f} u_{f}^{2}\right) A_{p},
$$

and a downward force $F_{D}$ equal to the static pressure $P_{s}$, cohesive force $F_{C}$, and the particle weight $W_{p}$,

$$
F_{D}=P_{s} A_{p}+F_{C}+V_{p}\left(\rho_{p}-\rho_{f}\right) g
$$

Hydrostatic pressure acts on both the top and bottom of the particle. At the point at which the particle would just begin to rise, the upward force equals the downward force, so that equation (2) equals equation (3). For spherical particles, the ratio of $V_{p}$ to $A_{p}$ is equal to $2 d_{p} / 3$, so that the above relationship simplifies to

$$
u_{f}=\sqrt{\frac{4}{3} g d_{p}\left(\frac{\rho_{p}}{\rho_{f}}-1\right)+\frac{4 F_{C}}{\pi d_{p}^{2}}} .
$$

Minimum critical velocity $u_{c}$, to pick up the solid particle of diameter $d_{p}$ from a sludge layer can be obtained when a cohesive force $F_{C}$ in eq. (4) is neglected.

$$
u_{c} \approx 3.617 \sqrt{d_{p}\left(\frac{\rho_{p}}{\rho_{f}}-1\right)}
$$

Rotational motion of the particle is negligible since the particle is small (about 1 to 20 microns). It should be noted that the model neglects inter-particle cohesion and static friction between the surface and a particle at rest based on an assumption that solids submerged within an open tank are loosely deposited during precipitation. In reality, the velocity required to overcome friction and cohesion can be considerably greater than that derived from this model, which accounts solely for weight and lifting force due to fluid momentum. In addition, cohesive force $F_{C}$ in eq. (4) is dependent on material characteristics associated with water/moisture content, consistency of the aggregate, and degree of solid fineness and uniformity since cohesive sludge materials deposited on the tank floor are always in contact with water, and they are kept compressed by the hydrostatic head of tank liquid level.

Experimental studies of scour criteria have been published in the literature. Graf (1971) presented an empirical correlation for the critical velocity required to initiate movement of a deposited particle. In the correlation, he used average fluid velocity rather than the bottom velocity, since most of the previous works on erosion studies used average velocity. The empirical correlation for critical velocity $\left(U_{c}\right)$ was made in terms of particle size $\left(d_{p}\right)$, liquid level $\left(H_{\ell}\right)$, and density $\left(\rho_{p}\right)$ of solid particle. 
$U_{c}=\left(\frac{H_{\ell}}{d_{p}}\right)^{0.1} \sqrt{2.5 g d_{p}\left(\frac{\rho_{p}}{\rho_{f}}-1\right)}=4.9523\left(\frac{H_{\ell}}{d_{p}}\right) \sqrt[0.1]{d_{p}\left(\frac{\rho_{p}}{\rho_{f}}-1\right)}$

Equation (6) was established with test data from various investigations. All the parameters used in eq. (6) are in SI unit. It is functionally similar to the theoretical formulation of equation (5), since the liquid level parameter is only weakly related to the critical velocity. Because of its empirical nature, equation (6) includes the influence of friction and particle-particle interactive forces. This, combined with its development in terms of average fluid velocity, is reflected in the larger coefficient than seen in equation (5). To apply equation (6) to the present work, it is assumed that for each grain size, a certain "critical velocity" exists, below which the particle will experience sedimentation, and above which it will be lifted from the non-cohesive solid layer.

\section{Critical Shear Criterion To Scour Solids}

The stress on tank wall due to shearing action of a flowing fluid was thought to be an important feature of initial scour or the critical condition for initial movement of a deposited particle. The abrasive friction due to wall shear is the key mechanism for the initial scour of particles from the wall surface. Given the small particle size in the present operating conditions, other influences such as particle-particle interactions and the effects of the particles on the continuous liquid phase are negligible.

The turbulent fluid-wall interaction is evaluated with a standard $\kappa-\varepsilon$ model. This model computes the turbulent eddy viscosity $v_{t}$ by solving two transport equations for $\kappa$ (turbulent kinetic energy) and $\varepsilon$ (rate of dissipation of turbulent energy). The literature shows that the turbulent eddies are constantly lifting particles into the fluid stream due to the fluctuations in velocity. When applying the wall shear mechanism to the mixing evaluation, it is assumed that the wall shear stress affects the initial scour or lifting-up of the solids lying at the bottom of the tank.

Graf (1971) recommended an empirical correlation for critical shear stress $\left(\tau_{w c}\right)$ to initiate the movement of deposited particles. In his correlation, he used mean particle size $\left(\bar{d}_{p}\right)$ as key parameter. A convincing shear stress versus grain size relationship could be represented with the simple relationship,

$\tau_{\text {wc }}=0.166 g\left(d_{p}\right)_{\text {avg }} \approx 1.6285\left(d_{p}\right)_{\text {avg }} \quad\left(N / m^{2}\right.$ or $\left.\mathrm{Pa}\right)$

Equation (7) was developed from various sources of data available in the literature. It applies to solid particles less than $3.4 \mathrm{~mm}$ in diameter. The mean particle diameter in equation (7) is in millimeters.

\subsection{Incipient Erosion Velocity}

When liquid flow passes over a stationary cohesive sludge mound containing solid particles, the flowing liquid is responsible for hydrodynamic forces being exerted on the individual particle of the mound. In this case the initial movement of the top layer of the mound is called critical or incipient condition of erosion. The degree of erosion resistance for a given particle size to the hydrodynamic forces of flowing fluid depends on the cohesion and adhesion forces, which are represented by $F_{C}$ in eq. (4). In this case, a further increase in the fluid momentum causes an increase in the magnitude of 
Page: $\quad 10$ of 48

hydrodynamic forces. Hence, for a particular stationary sludge mound, a condition is eventually reached at which particles in the movable bed are not able to resist the hydrodynamic forces and, thus, solids of a given size resting in the top layer start to be eroded.

The present case to estimate the incipient minimum erosion velocity considers a stationary bed consisting of cohesive solid particles of uniform size, and liquid flowing over it. The literature data show that large particles are more easily eroded by streams than smaller ones. This phenomenon becomes more pronounced with small particles since the cohesion forces existing between the particles increase as the latter decrease in size. Dallavalle (1948) cited the equation for the incipient velocity of silting erosion

$v_{\mathrm{ec}}=\frac{0.00656}{d_{p}}$

where $v_{e c}$ is the incipient eroding velocity in $\mathrm{ft} / \mathrm{sec}$, and $d_{p}$ the diameter of the particles in $\mathrm{mm}$. Incipient erosion velocities provided by eq. (8) are applicable to silting material, which contains small sizes of particles ranging from 5 (larger than clay) to 50 microns (close to very fine sand) in diameter.

Graf (1971) [Ref. 11] presented the literature data for the incipient erosion velocity as shown in Fig. 4. As can be seen in Fig. 4, there exists for each grain size a certain velocity below which it will experience sedimentation, while above a certain velocity, called critical scour velocity, it will be eroded. Fluid velocity between these two velocities will suspend or transport solids for each solid size. The results show that the current velocity $2.27 \mathrm{ft} / \mathrm{sec}$ will erode the sludge layer for the particle sizes larger than clay material (about 5 microns). Equation (6) shows that fluid velocity, particle size, specific gravity of particle, and tank liquid level are key parameters associated with particle suspension. It should be emphasized that the incipient velocity of erosion is actually dependent on the critical shear stress at which incipient sediment begins to move. The critical shear stress of actual cohesive materials contained in Tank 18 depends on the composition of the different sludge material, the particle-size distribution, the particles' shape, and the packing.

Table 2 demonstrates reasonable agreement between the approximate analysis described above and the present velocity criterion used for the suspension and removal operations of Tank 18. Minimum fluid velocity for suspending the sludge of Tank 18 in Savannah River Site (SRS) has been established as $2.27 \mathrm{ft} / \mathrm{sec}$ for the analysis. Thus, local fluid velocity at any distance from the nozzle is employed as a measure of the slurrying and mixing efficiency of the ADMP mixer in Tank 18. 
Table 2. Minimum velocities of particle pickup and removal for the various particle sizes (fluid density=1.2SG, particle density=2.0SG)

\begin{tabular}{|c|c|c|c|c|}
\hline $\begin{array}{c}\text { Tank } \\
\text { level } \\
\text { (inches) }\end{array}$ & $\begin{array}{l}\text { Particle } \\
\text { size } \\
\text { (microns) }\end{array}$ & $\begin{array}{l}\text { Minimum velocity } \\
\text { required to pick up } \\
\text { particle from } \\
\text { horizontal wall } \\
\text { surface computed } \\
\text { by eq. (6) (ft/sec) }\end{array}$ & $\begin{array}{l}\text { Minimum velocity } \\
\text { required to erode the } \\
\text { sludge mound } \\
\text { composed of uniform } \\
\text { sizes of solids (ft/sec) } \\
\text { [Ref. 11] }\end{array}$ & $\begin{array}{l}\text { Velocity criterion } \\
\text { used for particle } \\
\text { suspension and } \\
\text { transport for Tank } \\
18 \text { operations } \\
\text { [Ref. 2] }\end{array}$ \\
\hline \multirow{3}{*}{65} & 5 & 0.105 & 2.953 & \multirow{3}{*}{$\begin{array}{c}2.27 \mathrm{ft} / \mathrm{sec} \\
\text { (for sludge } \\
\text { removal) }\end{array}$} \\
\hline & 10 & 0.139 & 1.969 & \\
\hline & 20 & 0.184 & 1.312 & \\
\hline
\end{tabular}

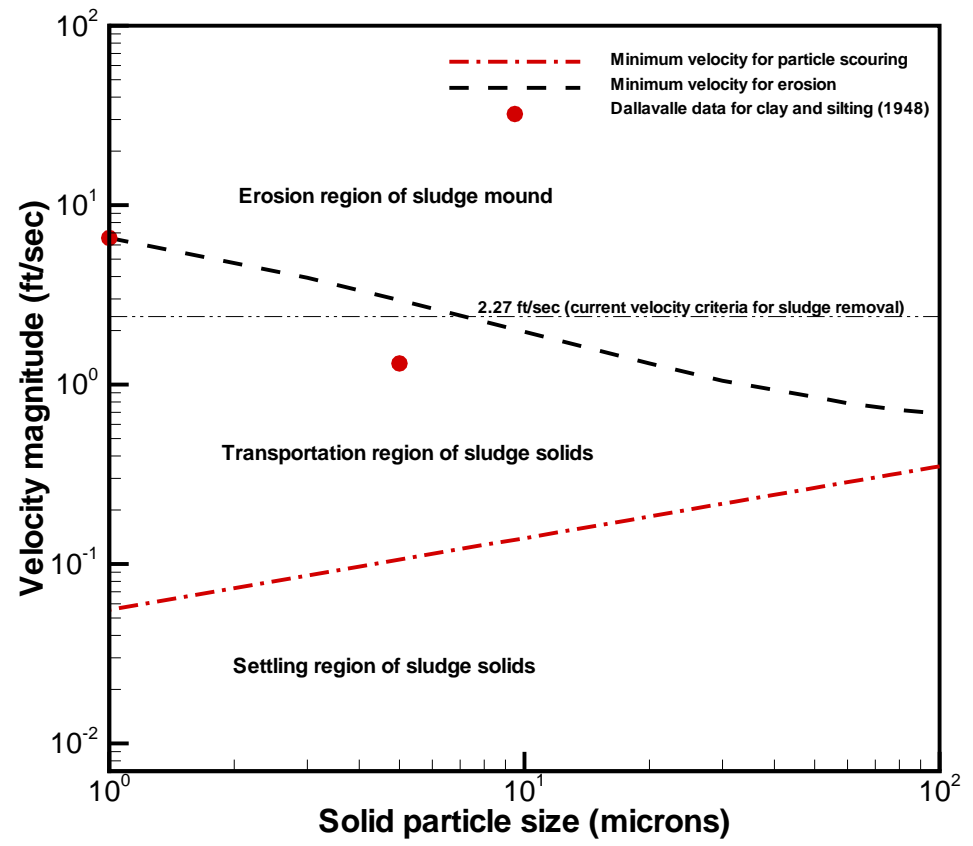

Figure 4. Velocity criteria for deposition, scouring, and erosion of sludge solids for the present operating conditions based on Graf's correlation (1971) [Ref. 11] and Dallavalle's data (1948) [14] 


\subsection{Modeling Approach and Analysis}

Based on the sludge suspension criteria established in the previous section, operations of Tank 18 waste removal with the ADMP mixer are simulated to estimate the ability to suspend sludge under potential operating conditions. Geometrical configurations and modeling boundary for the Tank 18 system to be modeled here are illustrated in Fig. 1. The ADMP mixer to be analyzed in the present work drives flow patterns for the flow domain of the $85 \mathrm{ft}$ tank. The pump suction is located at the bottom of the mixer pump as shown in Fig. 1.

The present analysis consists of two major parts as presented in Table 3 . One part is to develop the baseline model for the Tank 18 system, aiming at the evaluation of ADMP mixer performance for the nominal operating conditions with no sludge mounds as shown in Fig. 1. The second part is to perform flow simulations for the turbulent jet induced by the mixer and to estimate the extent of the slurry mixing zone for the Tank 18 system with the ADMP submerged at the center of the tank for various operating conditions with indexed position of pump nozzle. In this part, flow obstruction effect such as a cohesive sludge mound is also considered assuming that the moving boundary effects due to the sludge erosion are negligible.

The modeling work considers four basic cases with different boundary conditions to investigate how sensitive the flow patterns are to different tank levels and pump elevations. Flow obstruction in jet flow is also considered to examine the difference of flow evolutions between the two domains with and without sludge mound in terms of the jet dissipation and suspension efficiency for given reference design conditions. Detailed modeling domain and operating conditions for each model are provided in the subsequent section.

For the present analysis, a three-dimensional computational fluid dynamics (CFD) approach was taken to calculate flow velocity distributions for Tank 18. The commercial finite volume code, FLUENT [5], was used to create a prototypic geometry file in a nonorthogonal mesh environment. The model geometry was created using the body-fitted coordinate system and structured multi-block grids. For the pump performance analysis, the reference design conditions were considered as shown in Table 4 . The ADMP mixer is submerged inside a cylindrical tank that has 65 in high liquid level and $85 \mathrm{ft}$ in diameter as shown in Fig. 1.

In the present analysis, detailed wave motion of the free surface at the top of the tank was neglected for computational efficiency. That behavior does not have a significant impact on the flow patterns inside the slurry region in a deep tank. The fluid properties of water were evaluated at room temperature $\left(20^{\circ} \mathrm{C}\right)$. The flow conditions for the pump operations are assumed to be fully turbulent since Reynolds numbers for typical operating conditions are in the range of $10^{8}$ based on the pump nozzle inlet conditions. A standard two-equation turbulence model, the $\kappa-\varepsilon$ model [Ref. 5], was used since previous work [Ref. 2] showed that the two-equation model predicts the flow evolution of turbulent jet in a large stagnant fluid domain with reasonable accuracy. This model specifies the turbulent or "eddy" viscosity $\mu_{t}$ by the empirical equation.

$$
\mu_{t}=\left(\frac{C_{\mu} \rho_{f} k^{2}}{\varepsilon}\right)
$$


Table 3. CFD modeling approaches taken for the present analysis.

\begin{tabular}{|c|c|c|c|}
\hline $\begin{array}{l}\text { Analysis } \\
\text { Models }\end{array}$ & $\begin{array}{c}\text { Analysis } \\
\text { Cases }\end{array}$ & $\begin{array}{l}\text { Modeling } \\
\text { Approaches }\end{array}$ & Primary Purposes \\
\hline \multirow{4}{*}{$\begin{array}{l}\text { Tank } 18 \\
\text { Simulation } \\
\text { Models }\end{array}$} & $\begin{array}{l}\text { Case-I } \\
\text { (Reference } \\
\text { case) }\end{array}$ & $\begin{array}{c}\text { 3-D steady-state } \\
\text { with no sludge } \\
\text { mound }\end{array}$ & $\begin{array}{l}\text { To estimate the effective suspension zone for } \\
\text { Tank } 18 \text { with the ADMP mixer located at the } \\
\text { center of the tank with a } 65 \text { in liquid level and } \\
\text { to perform the sensitivity analysis of various } \\
\text { key parameters such as nozzle elevation, } \\
\text { pump flowrate, and fluid properties }\end{array}$ \\
\hline & Case-II & $\begin{array}{c}\text { 3-D steady-state } \\
\text { with no sludge } \\
\text { mound }\end{array}$ & $\begin{array}{l}\text { To estimate the effective suspension zone for } \\
\text { Tank } 18 \text { with the ADMP mixer located at the } \\
\text { center tank with } 90 \text { in liquid level and to } \\
\text { compare this case with that of a } 65 \text { in tank } \\
\text { level in terms of slurry mixing and suspension } \\
\text { capabilities }\end{array}$ \\
\hline & Case-III & $\begin{array}{c}\text { 3-D steady-state } \\
\text { with no sludge } \\
\text { mound }\end{array}$ & $\begin{array}{l}\text { To compare the effective mixing zone for } \\
\text { Case-I with the ADMP mixer located at the } \\
\text { center of the tank with a low liquid level ( } 40 \text { in } \\
\text { tank level) }\end{array}$ \\
\hline & Case-IV & $\begin{array}{c}\text { 3-D steady-state } \\
\text { with sludge } \\
\text { mound }\end{array}$ & $\begin{array}{l}\text { To estimate maximum wall shear on the } \\
\text { surface of cohesive sludge mound and to } \\
\text { compare the effective mixing zones for Case- } \\
\text { I and Case-IV under the same liquid level (65 } \\
\text { in tank level) }\end{array}$ \\
\hline
\end{tabular}

In eq. (9) $C_{\mu}$ is an empirical constant. In the present calculations, $C_{\mu}$ is 0.09 . Thus, the turbulent viscosity is computed by solving two transport equations for $k$ (turbulent kinetic energy) and $\varepsilon$ (rate of dissipation of turbulent energy). The governing equations to be solved for the present work are composed of one continuity equation, three momentum equations for the three component directions ( $x, y$, and $z$ directions), and two constitutive equations for the turbulence descriptions. The detailed descriptions for the governing equations and computational methods are provided in the previous work [Ref. 2]. The model is a full three-dimensional representation of the entire tank to capture significant phenomena related to the turbulent behavior of jet flow evolution.

Water was used to simulate the fluid in the tank assuming that it would give an acceptable representation of the flow patterns. The sensitivity studies were also performed using other fluid properties as well as water. Detailed geometrical and operating conditions of the full tank facility are provided in Table 4. Based on nozzle diameter and water properties, flow near the nozzle is clearly turbulent since the Reynolds number is about $4.65 \times 10^{8}$. At the same time, flow in regions far away from the nozzle is probably laminar. Nonetheless, the flow for the entire computational domain is assumed to be turbulent to give a reasonable representation of the liquid jet leaving the pump nozzle. The code cannot handle both laminar and turbulent flows in a single calculation, although they exist in real flow situations. 
Report: WSRC-TR-2003-00166

Date: $\quad$ 10/29/2003

18

Page: 14 of 48

The three-dimensional model was run in a steady-state mode for fixed pump conditions to allow the jet flow profile to develop steady state flow. For a fixed pump model, the pump is in a fixed orientation along a radial direction, so ADMP mixer with two 6-in discharge jets is located at the center of a horizontal plane at a given elevation in the tank. Geometrical configurations for the tank 18 system are shown in Fig. 1. Detailed descriptions of the tank models follow.

Table 4. Reference design and operating conditions used for the present analysis of Tank 18 model.

\begin{tabular}{|c|c|c|}
\hline \multicolumn{2}{|c|}{ Parameters } & Conditions \\
\hline \multicolumn{2}{|c|}{$\begin{array}{l}\text { Tank dimensions } \\
\left(D_{\text {tank }} \times H_{\text {tank }}\right)\end{array}$} & $\begin{array}{l}85 \mathrm{ft} \text { diameter } \times 65 \text { in liquid level } \\
\left(90 \text { or } 40 \text { in } \text { high }^{+}\right)\end{array}$ \\
\hline \multicolumn{2}{|c|}{ Mixing Pump } & Advanced Mixer Pump (as shown in Table 1) \\
\hline \multicolumn{2}{|c|}{ Pump nozzle diameter } & 6 in \\
\hline \multirow{2}{*}{$\begin{array}{l}\text { Pump position } \\
\text { inside the tank }\end{array}$} & Vertical elev. & 23 in (27in and 38 in) ${ }^{+}$above tank bottom \\
\hline & Horizontal loc. & Center of the tank \\
\hline \multicolumn{2}{|c|}{ Tank fluid temperature } & $20^{\circ} \mathrm{C}$ \\
\hline \multirow{2}{*}{\multicolumn{2}{|c|}{ Tank fluid }} & Water \\
\hline & & Slurry $^{++}$(density: 1.2 SG, viscosity: $2 \mathrm{cp}$ ) \\
\hline \multicolumn{2}{|c|}{ Nozzle flowrate for each nozzle } & 5200 gpm for ADMP \\
\hline \multicolumn{2}{|c|}{ Flow velocity at nozzle exit $\left(\mathrm{U}_{\mathrm{o}}\right)$} & $17.98 \mathrm{~m} / \mathrm{sec}^{*}$ \\
\hline \multicolumn{2}{|c|}{ Pump orientation } & Indexed operation \\
\hline
\end{tabular}

Note:

+ This is for the sensitivity run of the liquid level.

${ }^{++}$This fluid is only for sensitivity run.

* Fluid velocity at the exit of 6 in nozzle corresponding to $5200 \mathrm{gpm}$ flowrate

\section{Tank 18 Simulation Models with ADMP Mixer}

The Tank 18 models are for an $85 \mathrm{ft}$ diameter flat-bottomed cylindrical tank. A tank liquid level of 65 in was used as a reference condition as shown in Table 4 . The models also considered 90 in and 40 in liquid levels to investigate the impact of tank level on the flow patterns and sludge cleaning distance.

As discussed earlier, the ADMP mixer was used to mix the tank contents. The mixer has two horizontal discharge nozzles, each 6 in diameter with a $5200 \mathrm{gpm}$ flowrate. There is one suction location at the bottom of the pump for flow recirculation. The mixer is assumed to be located at the center of the tank and the centerline of the pump 
discharge nozzle 23 in above the tank bottom as shown in Fig. 1. A full threedimensional model of the entire tank was used to capture significant phenomena related to the turbulent behavior of jet flow dissipation.

Water was used to simulate the slurry. Detailed geometrical and boundary conditions of the full tank facility are provided in Table 4. The flow regime for the near-pump region was fully turbulent based on the nozzle diameter and water properties.

The flow for the entire computational domain is assumed to be turbulent to give a reasonable representation of the liquid jet leaving the pump nozzle. For the turbulence calculations, the standard $\kappa-\varepsilon$ model was used as described earlier. Governing equations for the entire computational domain were solved with FLUENT ${ }^{\mathrm{TM}}$. The calculations consisted of four different cases to simulate various operating and physical conditions for Tank 18 and to examine the sensitivities of the operating parameters and flow obstruction such as sludge mound with respect to the efficiency of sludge suspension and cleaning distance of waste removal. Table 5 provides detailed descriptions for all the cases considered here. Figure 5 shows modeling boundary and computational domain for the simulation of Tank 18 operation with fixed ADMP mixer including 45-ft wide and 23-in high sludge mound. The three-dimensional models were run in a steady-state mode for the fixed pumps to allow the jet flow to get a steady state flow pattern. For the fixed pump model, the pump is in a fixed orientation at the center of the tank. The ADMP mixer is located at 23 inches above the tank bottom as one of the reference conditions. Each nozzle is pointed directly at the wall of the tank. Detailed geometrical configurations for the pump model are shown in Fig. 1.

Geometrical simplifications and physical assumptions used in the Tank 18 models are listed as follows:

- Two discharge nozzles are $180^{\circ}$ apart, aligned in straight and opposite directions.

- The pump nozzle is stationary.

- The working liquid is water at room temperature $\left(20^{\circ} \mathrm{C}\right)$.

- The liquid region is bounded by a free surface at constant atmospheric pressure.

- The model is isothermal. No energy equation is calculated.

- The flow in the entire modeling domain is assumed to be turbulent to give a reasonable representation of the liquid jet leaving the pump nozzle.

- The wavy motion of the free surface due to the interaction with the discharge jet is neglected. Literature data [Ref. 4] show that the surface wave effect is negligible when the ratio of liquid height above the nozzle to nozzle diameter is larger than 2.5. For the ADMP mixer in Tank 18, the minimum ratio is about 2.2 for the 40 in liquid level case.

- The Case-IV model with flow obstruction simulated as a cohesive sludge mound does not consider the moving boundary effects due to the material erosion.

A three-dimensional computational model was developed and solved with FLUENT ${ }^{\mathrm{TM}}$ [Ref. 5]. The 85-ft tank with ADMP mixer located at 23 inches above the tank floor was filled to a liquid height of 65 inches as a reference model as shown in Table 5, and the boundary of the top liquid surface was fixed at constant atmospheric pressure. For typical three-dimensional computational domains of the referenced Tank 18 model (Case-I) and the model with 45-ft wide 23-in high sludge mound (Case-IV), non-uniform 
Report: WSRC-TR-2003-00166

Date: $\quad 10 / 29 / 2003$

18

Page:

16 of 48

hexahedral meshes of about 260,000 nodes were established. Two dimensional computational meshes for those two models are shown in Fig. 6.

Table 5. Detailed analysis cases and conditions for the three-dimensional Tank 18 models to estimate cleaning distances and flow patterns

\begin{tabular}{|c|c|c|}
\hline $\begin{array}{l}\text { Analysis cases for } \\
\text { Tank } 18 \text { models }\end{array}$ & $\begin{array}{l}\text { Simulation } \\
\text { method }\end{array}$ & Geometrical and operating conditions \\
\hline $\begin{array}{c}\text { Case-I } \\
\text { (Reference case) }\end{array}$ & Steady-state & $\begin{array}{ll}\text { - } & 5200 \mathrm{gpm} \text { each nozzle (6 in diameter) } \\
\text { - } & 65 \text { in tank liquid level } \\
\text { - } & \text { fixed pump direction } \\
\text { - } & \text { pump speed: full speed }(76 \%, 90 \%, \text { and } \\
& 95 \% \text { of full speed })^{*} \\
\text { - } & \text { pump elevation: } 23 \text { in }(27 \text { in })^{*} \\
\text { - } & \text { clean tank }\end{array}$ \\
\hline Case-II & Steady-state & $\begin{array}{l}5200 \text { gpm each nozzle (6 in diameter) } \\
\text { - } 90 \text { in tank liquid level } \\
\text { - } \quad \text { fixed pump direction with full speed (5200 } \\
\text { gpm per nozzle) } \\
\text { - } \quad \text { pump elevation: } 23 \text { in ( } 22 \text { in } 38 \text { in })^{*} \\
\text { - } \quad \text { clean tank }\end{array}$ \\
\hline Case-III & Steady-state & $\begin{array}{l}5200 \text { gpm each nozzle ( } 6 \text { in diameter) } \\
\text { - } 40 \text { in tank liquid level } \\
\text { - } \quad \text { fixed pump direction with full speed (5200 } \\
\text { gpm per nozzle) } \\
\text { - } \quad \text { clean tank }\end{array}$ \\
\hline Case-IV & Steady-state & $\begin{array}{l}5200 \text { gpm each nozzle (6 in diameter) } \\
\text { - } 65 \text { in tank liquid level } \\
\text { - } \quad \text { fixed pump direction with full speed (5200 } \\
\text { gpm per nozzle) } \\
\text { - } \quad \text { 45-ft wide sludge mound located at the jet } \\
\text { discharge side of tank wall (see Fig. } 5 \text { ) }\end{array}$ \\
\hline
\end{tabular}

Note:* The data was used for sensitivity study of each physical parameter. 


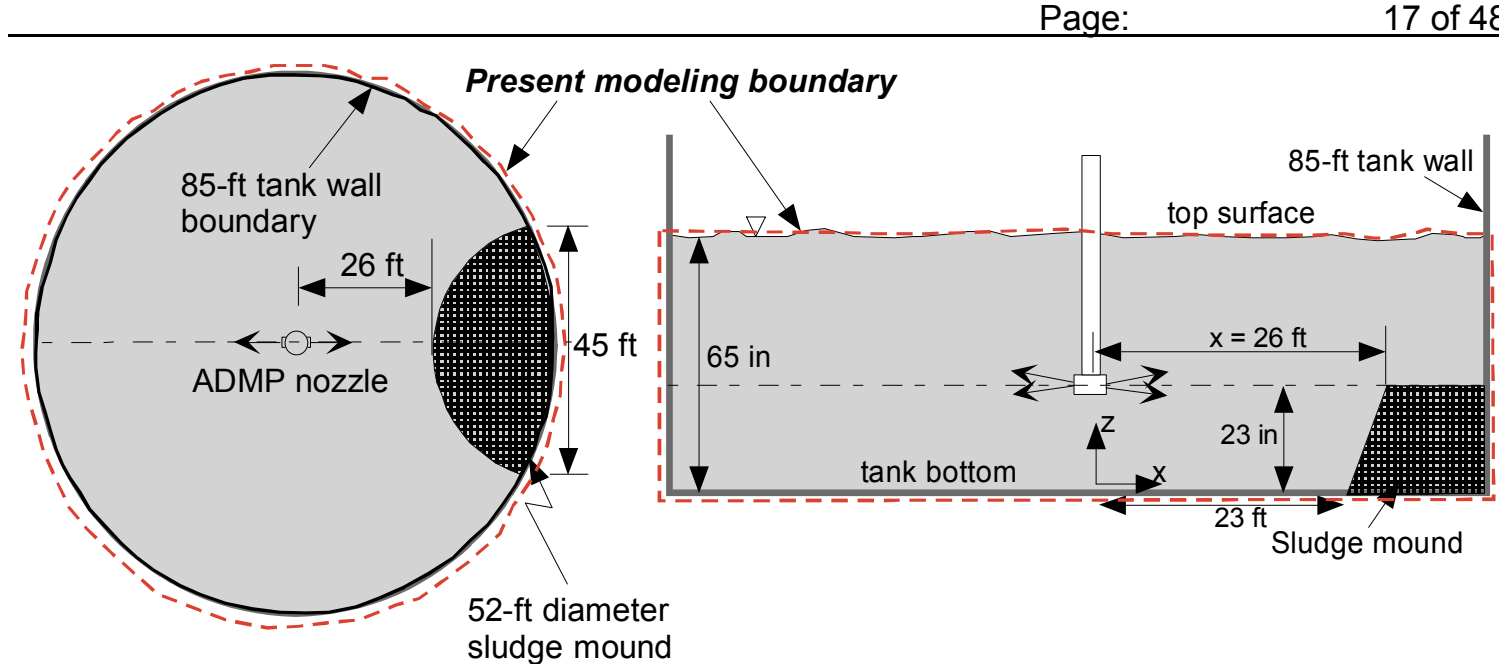

(Modeling boundary for the CFD simulation for sludge mound)

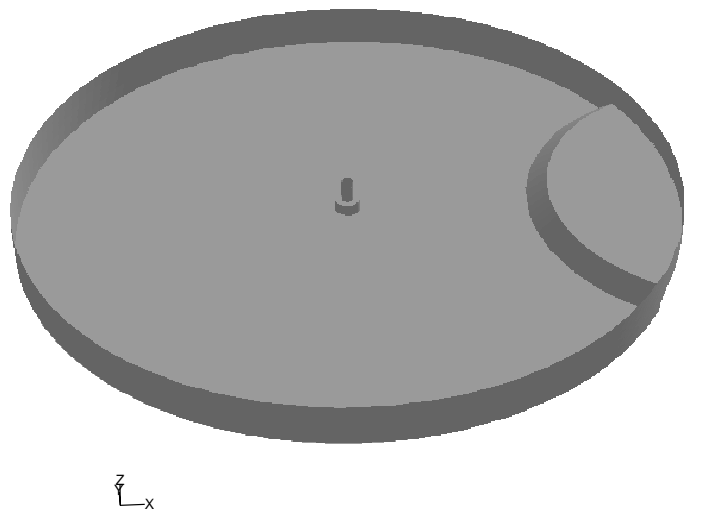

(Computational domain for the CFD simulation for sludge mound)

Figure 5. Modeling boundary and computational domain for the simulation of Tank 18 operation with fixed ADMP mixer including 45-ft wide and 23-in high sludge mound 
Report: WSRC-TR-2003-00166

Date: $\quad 10 / 29 / 2003$

18

Page: $\quad 18$ of 48
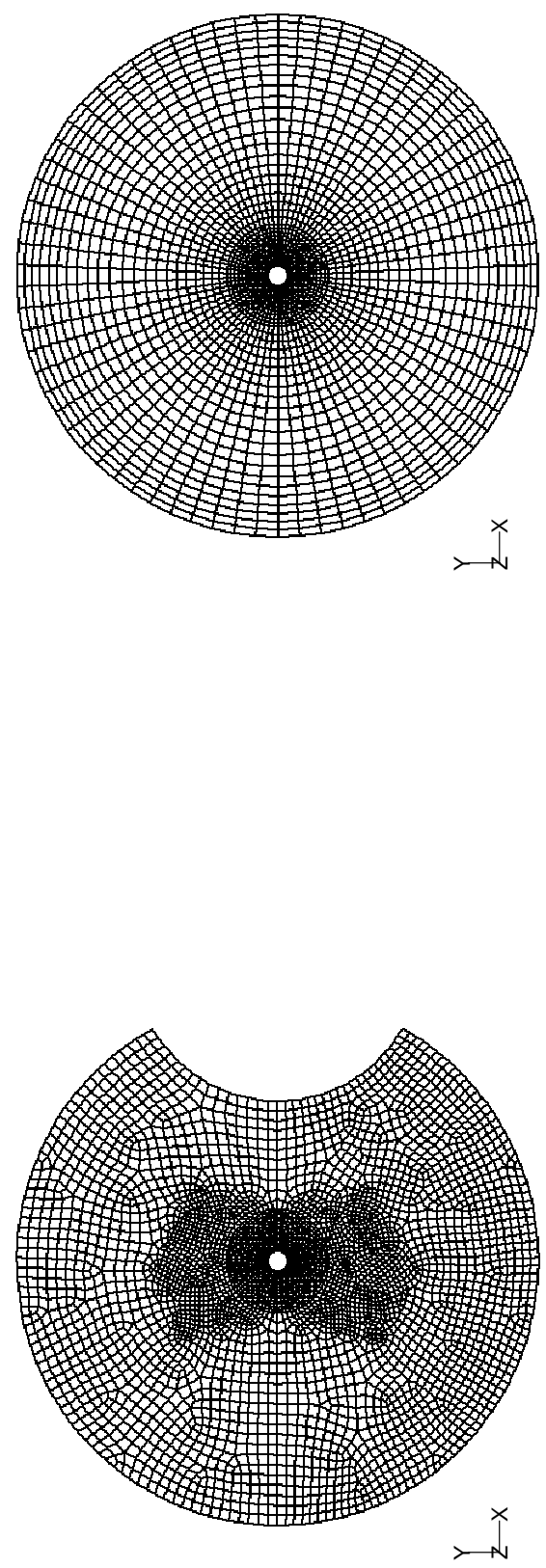

Figure 6. Non-uniform mesh nodes for the Tank 18 simulation models on $x-y$ computational domain 


\section{Results and Discussions}

CFD models were developed and analyses performed to estimate circulation flow patterns within Tank 18 and investigate steady-state flow responses to jet velocities and tank liquid levels for the ADMP mixer.

At the initial phase of the work, mesh sensitivity for the computational domain was assessed to determine whether the flow patterns calculated by the models were reasonable representations of jet flow evolution in the tank. From the nodalization study, an optimum number of about 260,000 nodes was established for the final analysis of the three-dimensional Tank 18 model. As shown in Fig. 6, very fine meshes, less than 0.2 in long, were used near the nozzle exit and suction inlet to capture the high velocity gradients in those locations.

Based on optimum meshes and boundary conditions, four different models have been developed, including the three different cases of the Tank 18 simulation models and the model considering the flow obstruction such as sludge mound. The flow patterns for the horizontal and vertical discharge planes of the computational domain for the Tank 18 model with the reference operating conditions, corresponding to Case-I of Table 5, are shown in Figs. 7 and 8 . Velocity contour plots for the nozzle plane of 23in elevation and the vertical plane crossing the ADMP nozzle are shown in Figs 9 and 10 . These figures show the mixing zones in red, which have higher than minimum suspension velocity, $2.27 \mathrm{ft} / \mathrm{sec}$, as shown in Fig. 4. The principal jet flow comes from the discharge nozzle toward the wall of the tank, to the right in Figs. 9 and 10 . The results show that jet velocity decays quickly near the exit of pump nozzle due mainly to the viscous dissipation through the fluid medium as shown in Figs. 11 and 12 . For an incompressible flow, the dissipative shear stress term can only exist when the vorticity is nonzero. The shear stress at the interface between the jet flow at the nozzle exit and the returning flow near the pump suction initiates fluid rotation. This is shown mathematically in the viscous term in the fluid momentum equation, which can be written as

$$
\begin{aligned}
(\nabla \bullet \sigma)_{\text {shear }} & =\mu \nabla \bullet(\nabla \vec{v}) \\
& =\mu \nabla(\nabla \bullet \vec{v})-\mu \nabla \times \vec{\Omega}
\end{aligned}
$$

In eq. (10), $\mu$ is dynamic viscosity and $\vec{\Omega}$ is the vorticity related to the fluid rotation. The first term of the right-hand side of eq. (10) is associated with fluid compressibilty, and the second term is related to the vortex formation generated by the evolution of jet flow. The present work considers an incompressible liquid, which means that the first term is zero. Divergence of the vorticity $\vec{\Omega}$ is identically equal to zero from the mathematical fact. That is

$$
(\nabla \cdot \vec{\Omega})=0
$$

There is the similarity between eq. (10a) and the equation of continuity for an incompressible fluid. The physical implication of eq. (10a) is that fluid rotation can not be created or destroyed within the interior of a fluid medium. The fluid vorticity can only be generated by the action of solid boundaries on the fluid through the phenomenon of zero slip. Thus, it is important to recognize that vorticity is always present in shear flow in the neighborhood of solid boundaries. 
Page: 20 of 48

It is interesting to investigate more closely the physical meaning of the interaction term $(\vec{\Omega} \bullet \nabla) \vec{v}$ in the vorticity equation for a viscous fluid since it plays an important role in the development of turbulence required for sludge suspension and mixing. Once vorticity is generated, the vorticity is dissipated in two ways. One way is the diffusion of vorticity in the fluid by the action of viscosity. The other is related to the term $(\vec{\Omega} \bullet \nabla) \vec{v}$ in the vorticity conservation equation for a viscous fluid. This term is non-zero only in a threedimensional flow field from the mathematical identity, and it represents the tilting and stretching of the vortex lines in a flow field. This results in a continuously changing pattern of velocity gradients and velocity components in the fluid. The vorticity interaction term physically represents the main process by which infinitesimal instabilities or small extraneous disturbances occurring in a laminar flow pattern can be transformed into three-dimensional turbulence. In this case, Reynolds number generally measures the relative magnitude of inertia forces compared with viscous forces for the assessment of the flow regime, but the critical value of Reynolds number required for flow transition is different depending on the flow conditions. For instance, at small values of Reynolds number some disturbances or instabilities generated as result of the vorticity interactions are more readily damped down by the viscous dissipation.

Thus, the vorticity is useful in interpreting fluid flow behavior because it tracks the effect of viscous forces. Pressure and gravity forces cannot be used in this way, because they act through the center of mass of a particle and cannot produce a rotation. The vortex formation results in jet dissipation near the inlet region of the pump nozzle because of high velocity gradients as shown in Fig. 13. This also results in the highest turbulence fluctuation due to increased turbulent kinetic energy near the discharge of the jet nozzle and the suction region of the mixer in the fluid domain of the tank. This flow fluctuation is considered in terms of turbulent intensity.

Turbulence intensity can be used as an indicator of local mixing to compare the ADMP mixer flows for the different cases listed in Table 5. The turbulence intensity $I$ is defined as the ratio of the root-mean-square of the velocity fluctuations to mean flow velocity. That is,

$I=\frac{\sqrt{\frac{1}{3}\left(u^{\prime 2}+V^{\prime 2}+w^{\prime 2}\right)_{\text {avg }}}}{V} \approx 0.8165 \frac{\sqrt{k}}{V}$

In eq. (11) $u^{\prime}, v^{\prime}$, and $w^{\prime}$ are local velocity fluctuations in the $\mathrm{x}, \mathrm{y}$, and $\mathrm{z}$ directions and $V$ is the mean velocity magnitude. The turbulence intensity is proportional to the square root of the turbulent kinetic energy $k$ for a given mean fluid velocity. Comparisons of the turbulence intensity distributions for the three different tank levels are shown in Fig. 14. The results show that the ADMP mixer submerged in higher tank level has better mixing performance with less momentum dissipation along the principal direction of the mixer, and therefore, better sludge removal capability in term of less momentum dissipation as discussed earlier.

From the results shown in Figs. 14 and 15, the velocity reduction rate along the discharge direction increases with increasing turbulence intensity. This is mainly related to the increased radial dispersion of fluid momentum, which leads to diminished axial velocity of the nozzle discharge flow. Thus, jet flows from the two nozzles of the ADMP mixer were dissipated quickly along the principal discharge directions as shown in Fig. 15. Figure 16 shows velocity distributions at 3 inches above the tank floor. Figure 17 
shows that the lower tank level has more momentum dissipation by wall shear than the higher tank level does. More detailed comparisons of velocity contour plots for the three different tank levels with a fixed 23-in pump elevation are made in Figs. 18 and 19. These results clearly show that fluid velocity for the lower tank level dissipates more quickly than the higher tank level under fixed pump elevation in an indexed mode of operation. It is noted that as soon as the flow exits the nozzle, four main circulation cells are generated around the tank, one on each side of the centerline for each nozzle as shown in Fig. 18. This circulating flow pattern will help to understand the suspension and removal of waste sludge. The results demonstrate that the higher tank level generates the stronger flow circulating patterns, resulting in a better suspension of sludge.

Table 6 summarizes the Tank 18 model results of maximum cleaning distance for the three different liquid levels with a fixed 23 -in pump nozzle elevation. The results show that the 40 -in model (Case-III) has the cleaning radius about $20 \%$ lower than the other cases because of the momentum dissipations by wall shear at the tank bottom and vortex motions near the pump inlet and exit regions, as discussed previously. The results shown in Figure 19 also support this statement.

Radial and vertical dissipations were investigated along the principal discharge direction of the ADMP mixer for the reference case (Case-I). Radial dissipation angle from the central discharge to local velocity of $2.27 \mathrm{ft} / \mathrm{sec}$ was found to be about $7^{\circ}$, which results in $14^{\circ}$ for both sides as shown in Fig. 20. This is consistent with the experimental observations for Tank 16 [Refs. 3, 18]. Vertical velocity distributions from top liquid surface to tank floor are shown in Fig. 21. The results show that velocity at the downstream region near the tank wall is developed near-uniformly along the vertical direction of the tank except for the wall boundary layer, which is consistent with the literature information [Ref. 10].

Table 6. Summary for the Tank 18 model results of maximum clearing distance (MCD) for three different tank levels considered in the analysis

\begin{tabular}{|c|c|c|c|}
\hline $\begin{array}{c}\text { Tank liquid level } \\
\text { (Cases of Table 5) }\end{array}$ & $\begin{array}{c}\text { Pump flowrate } \\
\text { per nozzle }\end{array}$ & $\begin{array}{c}\text { Nozzle } \\
\text { elevation }\end{array}$ & $\begin{array}{c}\text { Max. Clearing Distance* } \\
\text { (2.27 ft/sec) }\end{array}$ \\
\hline 40 in (Case-III) & $5200 \mathrm{gpm}$ & $23 \mathrm{in}$ & $32.0 \mathrm{ft}$ \\
\hline $65 \mathrm{in}($ Case-I) & $5200 \mathrm{gpm}$ & $23 \mathrm{in}$ & $41.6 \mathrm{ft}$ \\
\hline $90 \mathrm{in}($ Case-II) & $5200 \mathrm{gpm}$ & $23 \mathrm{in}$ & $41.6 \mathrm{ft}$ \\
\hline
\end{tabular}

Note: * MCD was defined as the distance from the center of the pump to the point at which local velocity reaches minimum suspension velocity, $2.27 \mathrm{ft} / \mathrm{sec}$. 
Report: WSRC-TR-2003-00166

Date: $\quad 10 / 29 / 2003$

18

Page: 22 of 48

Sensitivity runs for different pump elevations under the 65 in tank level were performed to find better clearing capabilities of the ADMP mixer from a fixed pump position for given operating conditions. The results for the Case-I model are summarized in Table 7. Figure 22 and Figure 23 show sensitivity results of different pump elevations for 90 in tank level (Case-II) at three different elevations. The results show that for a given tank level, the lower pump elevation provide a better mixing performance in terms of local velocity requirement for solid suspension.

Table 7. Summary for the model results of maximum clearing distance (MCD) for two different elevations of pump nozzle considered in the analysis

\begin{tabular}{|c|c|c|c|c|}
\hline $\begin{array}{c}\text { Pump speed } \\
\text { (Cases) }\end{array}$ & $\begin{array}{c}\text { Pump flowrate } \\
\text { per nozzle }\end{array}$ & $\begin{array}{c}\text { Nozzle } \\
\text { elevation }\end{array}$ & $\begin{array}{c}\text { Liquid level } \\
\text { (Nozzle size) }\end{array}$ & $\begin{array}{c}\text { Max. Clearing } \\
\text { Distance* } \\
\text { (2.27 ft/sec) }\end{array}$ \\
\hline $\begin{array}{c}\text { Full speed } \\
\text { (Case-I) }\end{array}$ & $5200 \mathrm{gpm}$ & $27 \mathrm{in}$ & $\begin{array}{c}65 \mathrm{in} \\
(6 \mathrm{in})\end{array}$ & $40.2 \mathrm{ft}$ \\
\hline $\begin{array}{c}\text { Full speed } \\
\text { (Case-I) }\end{array}$ & $5200 \mathrm{gpm}$ & $23 \mathrm{in}$ & $\begin{array}{c}65 \mathrm{in} \\
(6 \mathrm{in})\end{array}$ & $41.6 \mathrm{ft}$ \\
\hline
\end{tabular}

Note: * MCD was defined as the distance from the center of the pump to the point at which local velocity reaches minimum suspension velocity, $2.27 \mathrm{ft} / \mathrm{sec}$.

Sludge removal capability was evaluated for various pump speeds with all other parameters fixed using the reference model (Case-I). The reference liquid level was 65 in as shown in Table 4. The pump was assumed to be stationary. In this case, nozzle flowrate corresponding to each pump speed was considered for the modeling calculations. The modeling results show that the maximum cleaning distance decreases by about $1 \mathrm{ft}$ at the pump nozzle elevation of 23 in above tank bottom when the ADMP speed is reduced by about $25 \%$ from the full speed. The detailed results are summarized in Table 8 . Velocity distributions for the four different pump flowrates at two different elevations, pump nozzle elevation (23 in above the tank floor) and near tank bottom ( 3 in above the tank floor), are compared in Figs. 24 and 25.

The Case-IV model was considered to examine the impact of flow patterns due to the presence of sludge mound near the wall. Figure 5 shows shape and size of the sludge mound as modeled in the present work. Flow patterns for the Tank 18 system are compared between the models with and without sludge mound under an indexed ADMP operation located at the center of the tank as shown in Fig. 26 . Figure 27 presents velocity contour plots corresponding to the flow patterns of Fig. 26. The results show that flow fluctuations for the Case-IV model are increased due to the presence of flow obstruction, compared to those of the Case-I model. Figure 28 compares the flow fluctuations on the horizontal discharge plane of the tank between those two cases in terms of turbulence intensity. 
Table 8. Summary for the Tank 18 model results of maximum clearing distance (MCD) for different pump speeds considered in the analysis

\begin{tabular}{|c|c|c|c|c|}
\hline Pump speed & $\begin{array}{c}\text { Pump flowrate } \\
\text { per nozzle }\end{array}$ & $\begin{array}{c}\text { Nozzle } \\
\text { elevation }\end{array}$ & $\begin{array}{c}\text { Liquid level } \\
\text { (Nozzle size) }\end{array}$ & $\begin{array}{c}\text { Max. Clearing } \\
\text { Distance* } \\
\text { (2.27 ft/sec) }\end{array}$ \\
\hline $\begin{array}{c}\text { Full speed } \\
(1185 \mathrm{rpm})\end{array}$ & $5200 \mathrm{gpm}$ & $23 \mathrm{in}$ & $\begin{array}{l}65 \mathrm{in} \\
(6 \mathrm{in})\end{array}$ & $41.6 \mathrm{ft}$ \\
\hline $\begin{array}{c}95 \% \text { of full speed } \\
(1126 \mathrm{rpm})\end{array}$ & $4940 \mathrm{gpm}$ & $23 \mathrm{in}$ & $\begin{array}{l}65 \mathrm{in} \\
(6 \mathrm{in})\end{array}$ & $41.5 \mathrm{ft}$ \\
\hline $\begin{array}{c}90 \% \text { of full speed } \\
(1067 \mathrm{rpm})\end{array}$ & $4680 \mathrm{gpm}$ & $23 \mathrm{in}$ & $\begin{array}{l}65 \mathrm{in} \\
(6 \mathrm{in})\end{array}$ & $41.4 \mathrm{ft}$ \\
\hline $\begin{array}{c}76 \% \text { of full speed } \\
(900 \mathrm{rpm})\end{array}$ & $3950 \mathrm{gpm}$ & $23 \mathrm{in}$ & $\begin{array}{l}65 \mathrm{in} \\
(6 \mathrm{in})\end{array}$ & $40.6 \mathrm{ft}$ \\
\hline
\end{tabular}

Note: * MCD was defined as the distance from the center of the pump to the point at which local velocity reaches minimum suspension velocity, $2.27 \mathrm{ft} / \mathrm{sec}$.

As shown in Fig. 29, velocity distributions for the vertical plane crossing the pump nozzle are compared between the two cases, Case-I and Case-IV. It is noted that fluid momentum for the Case-IV model is dissipated more quickly than the Case-I because of the viscous boundary effect of wall shear as evidenced by eq. (10). As shown in Fig. 30, the sludge removal capability is about the same within about $24 \mathrm{ft}$ distance from the pump, but the velocity difference between the two cases becomes larger as the distance increases from $25 \mathrm{ft}$ to the tank wall (site of the sludge mound). This is mainly due to the larger momentum dissipation from the wall surface of solid obstruction for the case-IV model shown in Fig. 5. Figure 31 shows the degree of fluid rotations depending on tank liquid level and the presence of the flow obstruction inside the fluid domain. It is important to note that the presence of sludge mound inside the fluid domain provides a strong indication of fluid rotation on the top surface of tank, which is just above the sludge mound. The low tank level is 40 in for Case-III. The results are also compared in the figure. The high tank level (Case-I or Case-II) is generally more efficient than the other (Case-III) in terms of sludge cleaning distance because of less momentum dissipation during flow evolution of the ADMP jet.

As mentioned earlier, the Case-IV model was considered to estimate maximum wall shear associated with potential erosion capabilities of the ADMP jet in case of a cohesive sludge mound located on the tank floor. The soild particles of the cohesive mound may not exist in a dispersed state, but rather in an aggregate one. In this case, the particle-size distribution is an essential characteristics of the cohesive material. Its range might include everything from sand, with $d_{p} \approx 2 \mathrm{~mm}$, to clay, with $d_{p} \leq 2$ microns. Thus, surface conditions of the mound are different depending on its particle size so that critical conditions to erode the surface are dependent on the surface roughness and the moisture content of the sludge aggregate. Detailed results for various roughness heights of the sludge mound surface are summarized in Table 9. 
18

Page: $\quad 24$ of 48

Table 9. Maximum wall shear stress created by ADMP mixer jet for the sludge mound used for the present CFD simulation

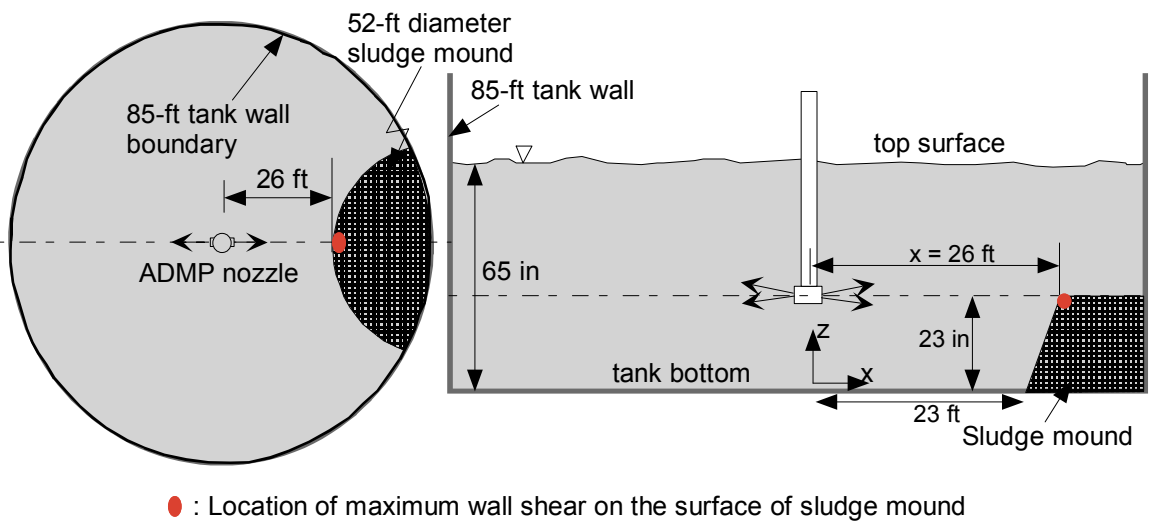

\begin{tabular}{|c|c|c|}
\hline $\begin{array}{l}\text { Surface condition of } \\
\text { sludge mound (absolute } \\
\text { roughness height)* }\end{array}$ & $\begin{array}{l}\text { Max. wall shear stress } \\
\text { on sludge mound created } \\
\text { by ADMP jet }\end{array}$ & $\begin{array}{l}\text { Min. shear stress } \\
\text { required to pick up 10- } \\
\text { micron solid [11] }\end{array}$ \\
\hline Smooth surface & $\sim 15 \mathrm{~Pa}$ & \multirow{3}{*}{$\begin{array}{l}0.02 \mathrm{~Pa} \text { (for non-cohesive } \\
\text { material) } \\
\sim 12 \mathrm{~Pa} \text { (for cohesive Texas } \\
\text { clay containing } 50 \% \\
\text { moisture content) }\end{array}$} \\
\hline $\begin{array}{l}\text { Rough concrete } \\
\qquad(0.01 \mathrm{ft})\end{array}$ & $\sim 27 \mathrm{~Pa}$ & \\
\hline $\begin{array}{l}\text { Revetted surface } \\
(0.03 \mathrm{ft})\end{array}$ & $\sim 33 \mathrm{~Pa}$ & \\
\hline
\end{tabular}

Note:* Rohsenow and Choi (1961) [Ref. 12]

** Maximum wall shear located at the top edge of the sludge mound exposed to the ADMP jet as shown above.

The results show that the sludge mound with larger solids can be eroded easier than the one with smaller solids. This is consistent with the literature data as shown in Fig. 4. Typical shear distributions induced by the ADMP jet are presented in Fig. 32 . The results show that maximum wall shear stress is located at the front nose of sludge mound exposed to the jet, leading to the most erosive site for the sludge mound considered here.

Most analyses have been performed using water as one of the reference operating conditions. Different fluid properties, which are similar to typical slurry fluids in Tank 18 as shown in Table 4, were used to examine the sensitivity of the flow patterns to these changes. The results show that the flow patterns are not sensitive to changes of fluid properties. At the discharge plane, there are no apparent differences in flow evolution. At the lower elevation 3 in below the pump nozzle, slurry flow around the horizontal discharge direction of the nozzle dies out slightly more quickly than water since radial diffusion is increased relative to convection when the fluid viscosity is increased from water $(1 \mathrm{cp})$ to slurry $(2 \mathrm{cp})$. It is noted that the radial flow behavior induced by the slurry 
is larger than that of water because of the increased diffusion in the momentum transport. However, when the maximum clearing distance (MCD) is defined as the distance over which the jet velocity exceeds the minimum suspension velocity, differences in the MCD between water and slurry are negligible. These results are summarized in Table 10.

Table 10. Sensitivity results for different fluid properties in the Tank 18 model $^{* *}$ in terms of maximum clearing distance (MCD)

\begin{tabular}{|c|c|c|c|}
\hline $\begin{array}{c}\text { Pump position } \\
\text { (Liquid level) }\end{array}$ & Tank fluid & $\begin{array}{c}\text { Nozzle velocity } \\
\text { (ft/sec) }\end{array}$ & $\begin{array}{c}\text { Max. Clearing Distance* } \\
\text { (2.27 ft/sec) }\end{array}$ \\
\hline $\begin{array}{c}23 \text { in above tank } \\
\text { bottom } \\
\text { (65 in) }\end{array}$ & Water & 58.99 & $41.6 \mathrm{ft}$ \\
\cline { 2 - 4 } & $\begin{array}{c}\text { Slurry } \\
\text { (1.2sg and 2cp) }\end{array}$ & 58.99 & $41.5 \mathrm{ft}$ \\
\hline
\end{tabular}

Note: * MCD was defined as the distance from the center of the pump to the point at which local velocity reaches minimum suspension (or specified) velocity.

** Operating conditions was defined in Table 1.

As discussed with the modeling results earlier, when fluid velocity is used as a scouring criterion to pick up and suspend sludge, flow fields induced by the ADMP mixer under the reference operating conditions defined in Table 4 are adequate for the sludge removal operation of Tank 18 . The results show that low tank level and high pump elevation provide smaller cleaning capabilities with respect to the reference conditions (Case-I), which are 5200 gpm pump flowrate per nozzle under 23 in elevation and 65 in tank level.

The primary goal of the Tank 18 model is to estimate the maximum clearing capability of the ADMP mixer from a fixed pump for given operational conditions. The cases used to evaluate this capability are defined in Table 5. This information will assist in the sludge suspension and removal plans for Tank 18 operations. The steady-state flow patterns on the horizontal discharge plane follow a series of parabolic curves similar to that of a free jet [Refs. 2, 9]. Vertical velocity profiles are changed from a bell-shaped curve near the exit of the nozzle to a near-uniform velocity near the tank wall boundary. This is consistent with literature data [Ref. 9]. Detailed horizontal and vertical velocity profiles are shown in Figs. 20 and 21, respectively.

It is important to recognize that local velocity is not the only parameter affecting the ability of the liquid stream to suspend sludge or aggregate materials when tank sludge has spatially non-uniform structure and characteristics of materials, or it is composed of cohesive aggregate. The length of time that the sludge is exposed to the liquid stream is also important in suspending cohesive sludge, and this effect is not captured in the present analysis. A longer exposure time, as would be the case for an indexed pump rather than a continuously rotating pump, could reasonably be expected to result in greater suspension or erosion of the sludge layer at a given pump position. Thus, exposure time for an indexed pump is determined by the previous experimental data and observations. 
18

Page: $\quad 26$ of 48

From the previous results for Tank 16 operations with $0.25 \mathrm{rpm}$ of average rotational slurry pump [Ref. 3], the pump operating time of about 600 hours was required to get cleaning radius of 42.5 feet. These data are applied to the present Tank 18 operations with fixed pump orientation since the CFD simulation results show that the steady-state cleaning distance covers the sludge mound area for potential operating conditions. In this case, the main assumption was that material characteristics of Tank 18 sludge is similar to that of Tank 16 sludge.

The mixing time for the pump operation with the fixed pump orientation aiming at the sludge mound was estimated using the Tank 16 data [Ref. 3]. From the present modeling results, the jetted spread angle was found to be about $14^{\circ}$ as illustrated in Fig. 33. These results are consistent with the previous one [Ref. 15]. For the present operating conditions with fixed ADMP, the pump operating time can be estimated by the equation. That is,

$$
t=t_{t k 16}(x)\left(\frac{\theta}{360}\right) N_{n}
$$

In eq. (12) $t_{\text {tk } 16}(x)$ is the pump operating time at the cleaning radius of $x \mathrm{ft}$, which can be obtained from Tank 16 data [Ref. 3]. $\theta$ and $N_{n}$ are jet spread angle and number of discharge nozzles for each pump, respectively. When the current indexed operating condition for ADMP is given as $\theta=14^{\circ}$, and $t_{t k 16}(x=42.5 f t)=600 \mathrm{hrs}$ is provided to eq. (12) by the previous data [Ref. 15], about 2 days' pump operation time is required for each indexed pump orientation in order to suspend cohesive materials.

All the results for the Tank 18 models show that horizontal and vertical velocity profiles and characteristics of flow evolution along the downstream flow direction are consistent with literature data. Summary results for qualitative velocity profiles are shown in Fig. 34. From the present analysis, it is concluded that the higher tank level and lower pump elevation are generally more efficient than the other in terms of sludge removal capability when other operating conditions remain the same. 


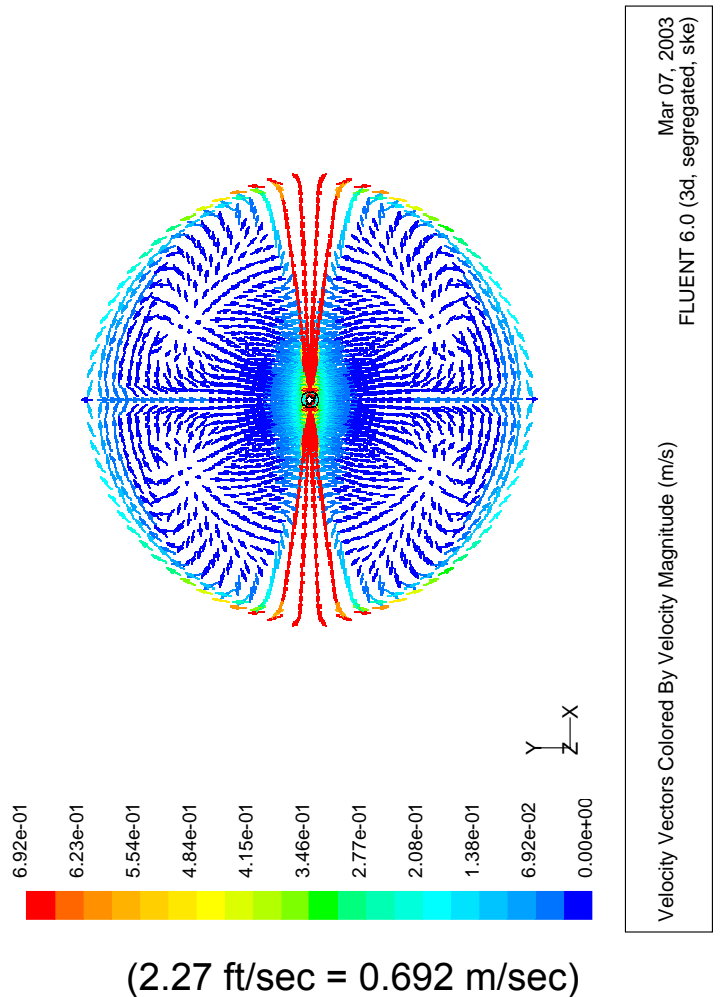

Figure 7. Flow patterns around the pump nozzle at the elevation of pump nozzle (23in from the tank bottom)

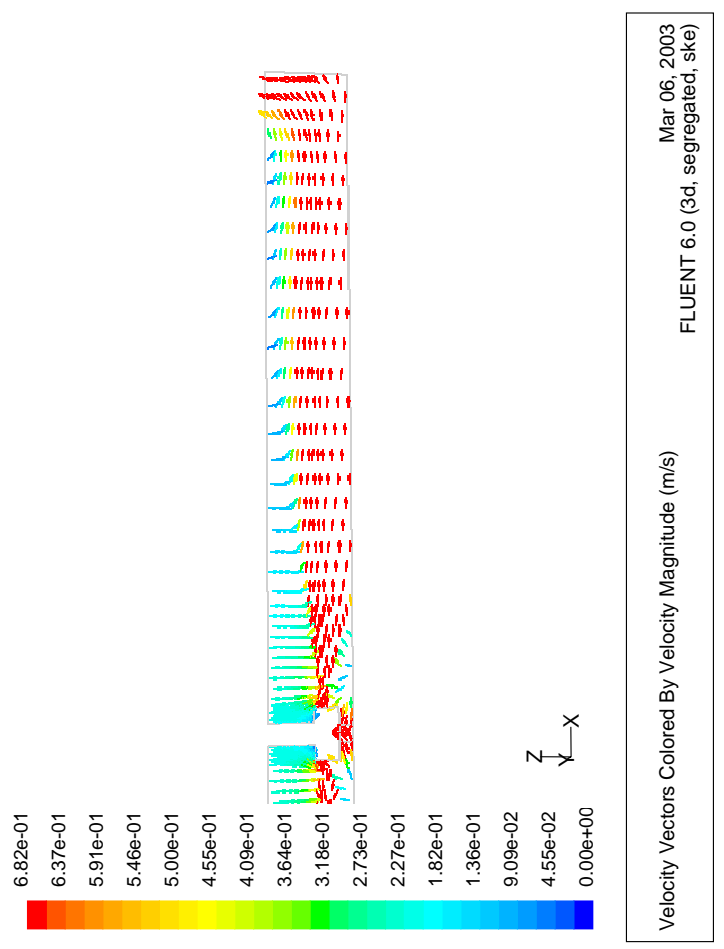

Figure 8. Flow patterns around the pump nozzle at the center-plane of pump nozzle 
Report: WSRC-TR-2003-00166

Date: $\quad 10 / 29 / 2003$

18
WESTINGHOUSE SAVANNAH RIVER COMPANY

EVALUATION OF SLUDGE REMOVAL CAPABILITIES FOR ADMP MIXER IN TANK Page: $\quad 28$ of 48

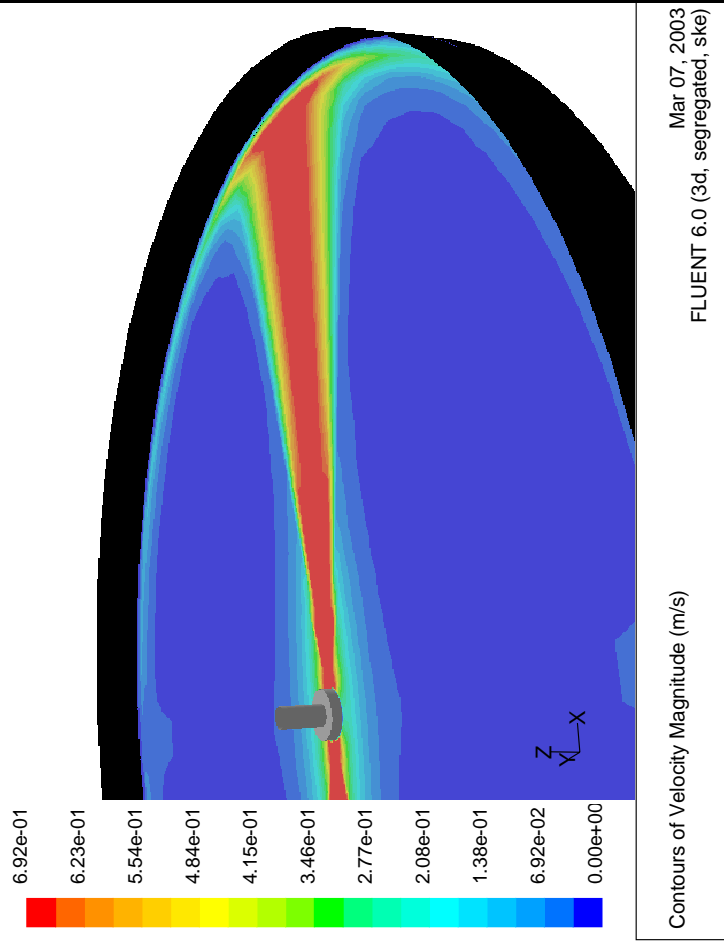

Figure 9. Velocity contour plot around the pump nozzle at the elevation of pump nozzle (23in from the tank bottom)

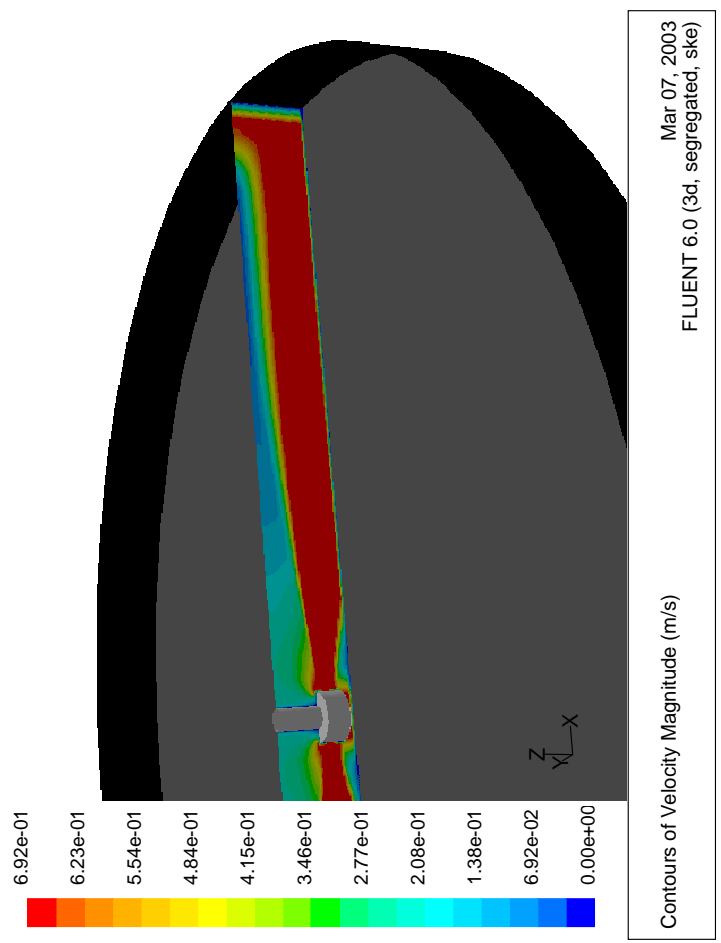

Figure 10. Velocity contour plot along the pump discharge direction at the center-plane of Tank 18 


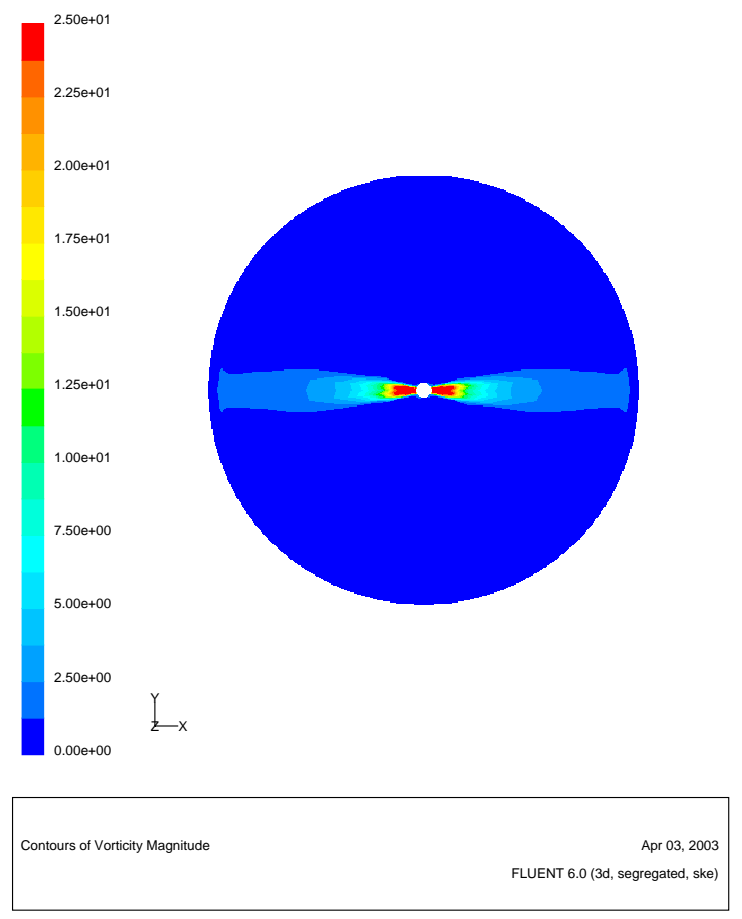

Figure 11. Vorticity distributions around the pump nozzle at the elevation of pump nozzle (23in from the tank bottom)
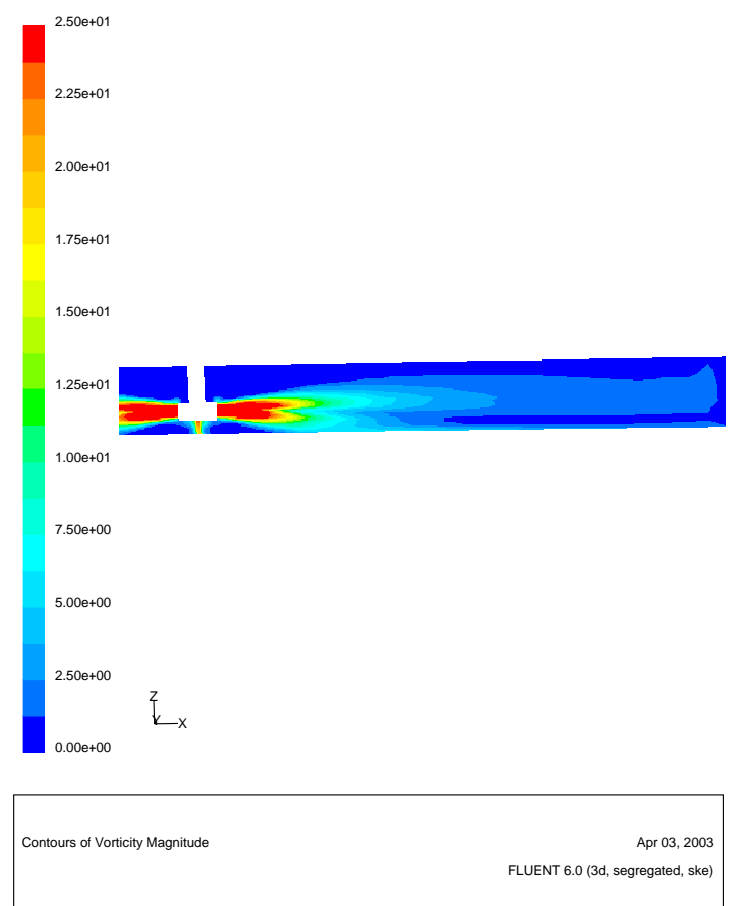

Figure 12. Vorticity distributions along the pump discharge direction at the center-plane of pump nozzle (23in from the tank bottom) 


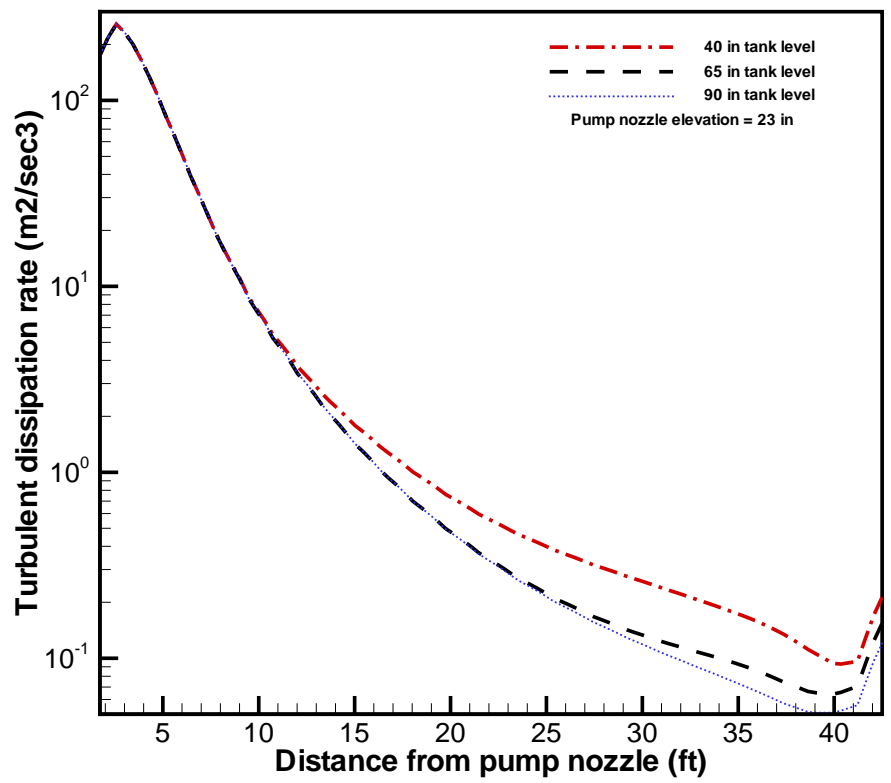

Figure 13. Comparison of turbulent dissipation rates for various tank levels with fixed pump elevation along the pump discharge direction at the 23-in elevation of pump nozzle from the tank bottom

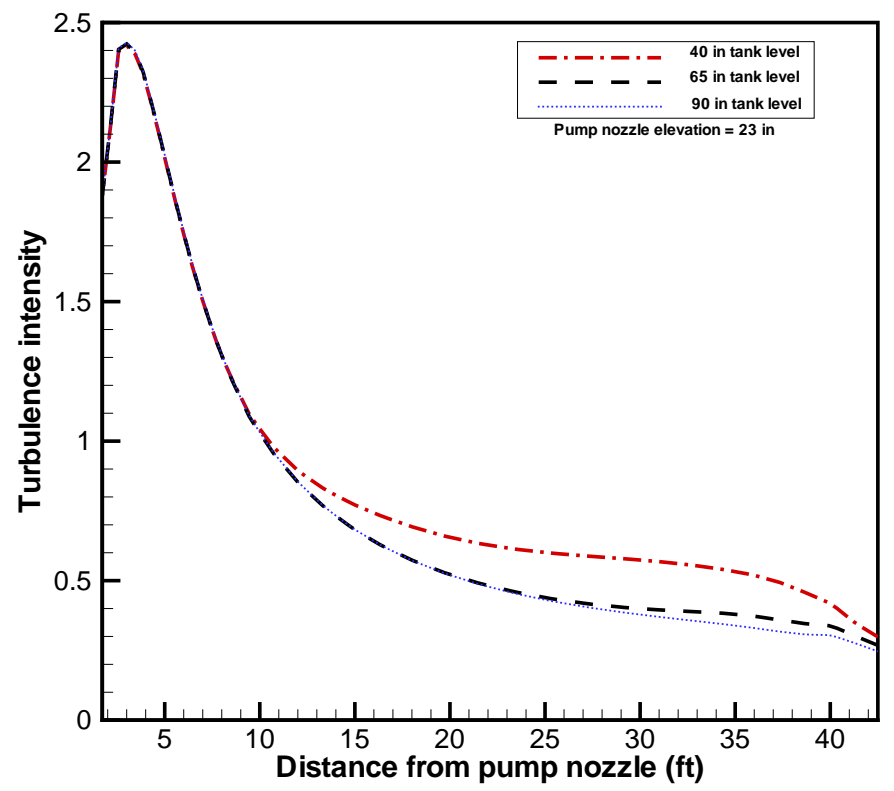

Figure 14. Comparison of turbulent intensities for various tank levels with fixed pump elevation along the pump discharge direction at the 23-in elevation of pump nozzle from the tank bottom 


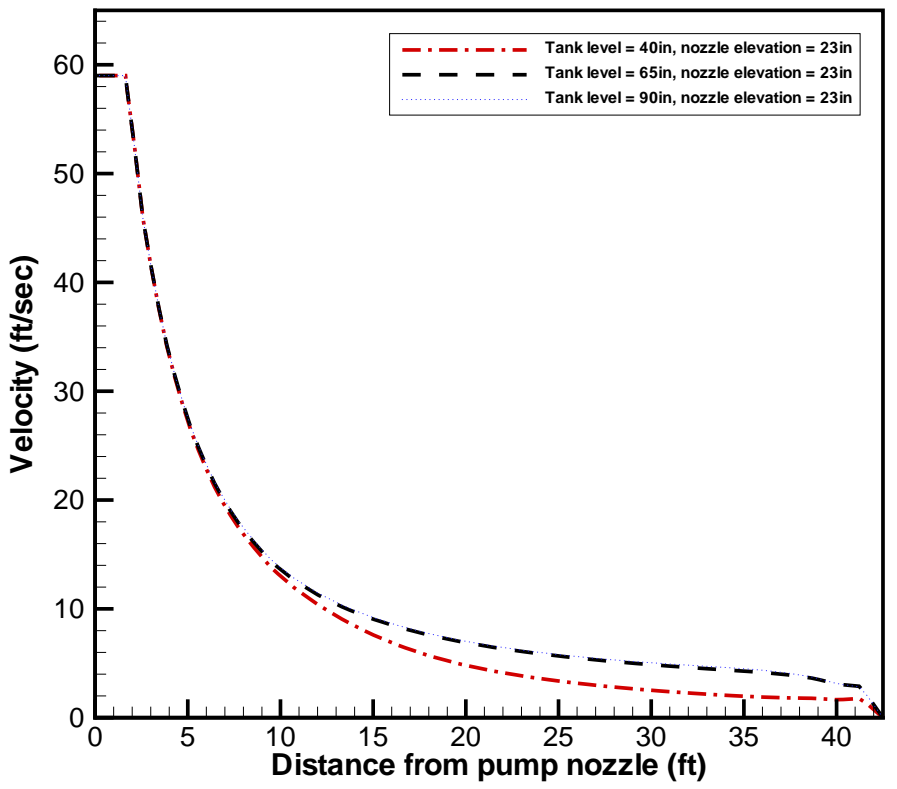

Figure 15. Comparison of velocity distributions along the pump discharge direction from pump nozzle to tank wall at the 23-in elevation of pump nozzle from the tank bottom

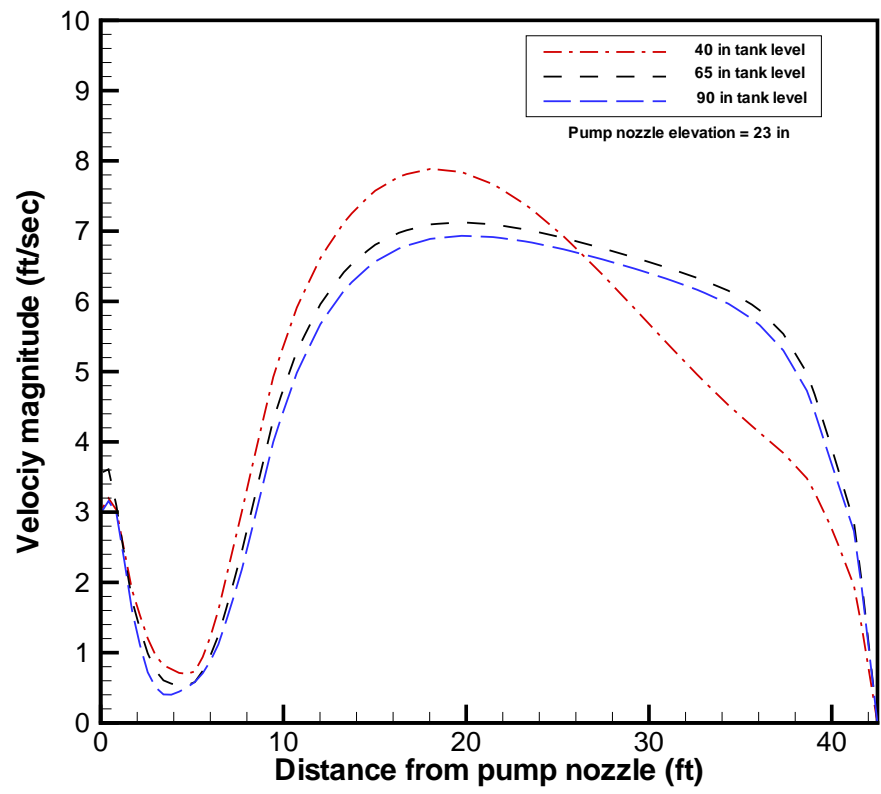

Figure 16. Comparison of local velocity magnitudes for various tank levels along the radial direction from pump nozzle to tank wall at 3-in elevation from the tank bottom 


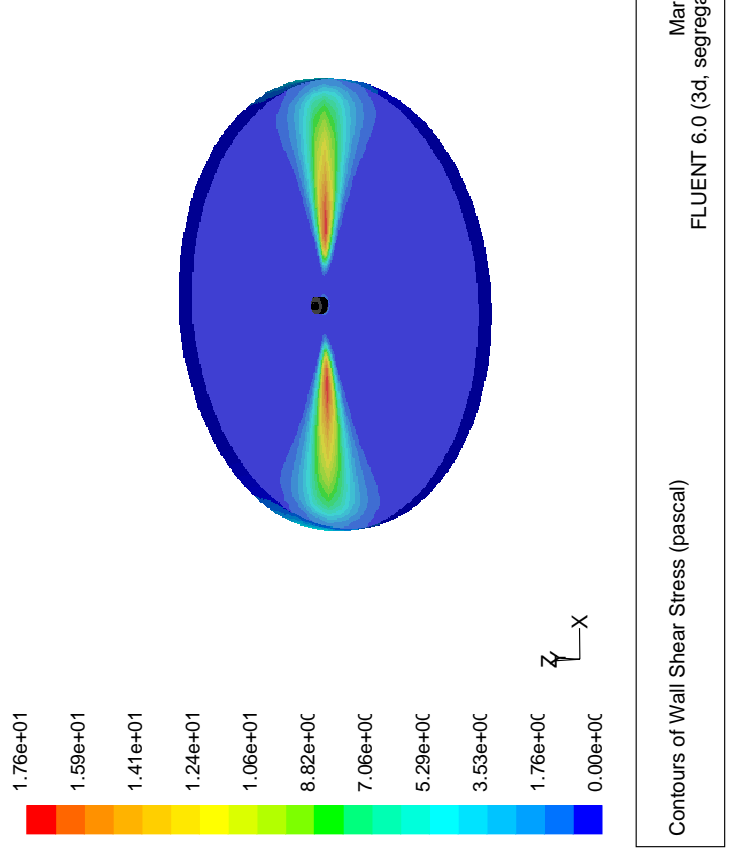

(40 in tank level with 23 in nozzle elevation: $\max$. wall shear $=18 \mathrm{~Pa}$ )

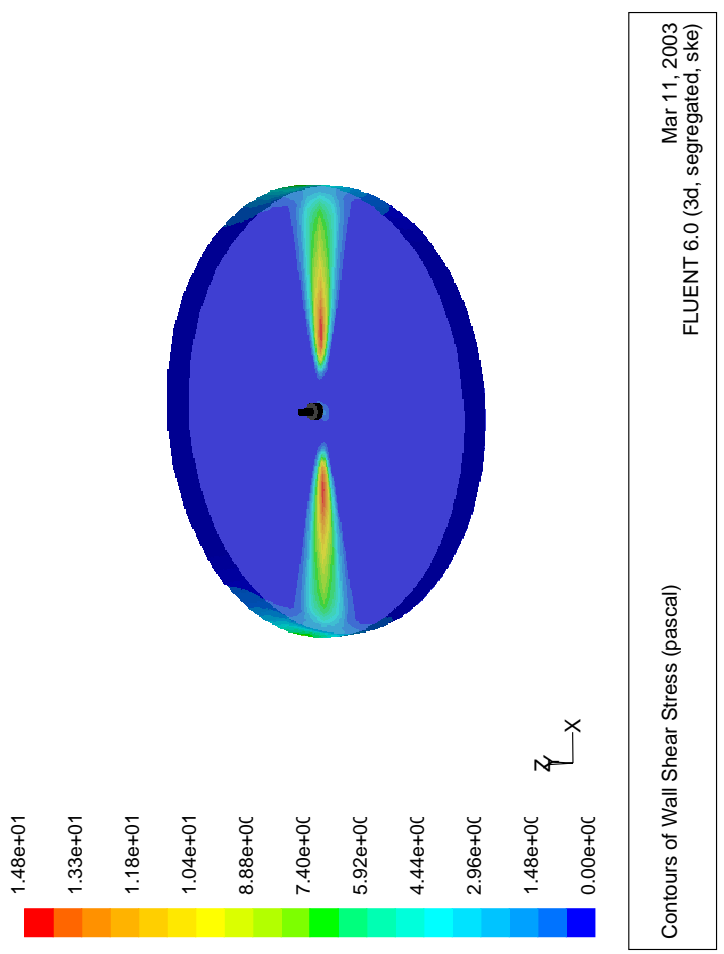

(65 in tank level with 23 in nozzle elevation: max. wall shear $=15 \mathrm{~Pa}$ )

Figure 17. Comparison of wall shear distributions around the wall of the 85 -ft tank between two different tank levels with fixed ADMP operation 


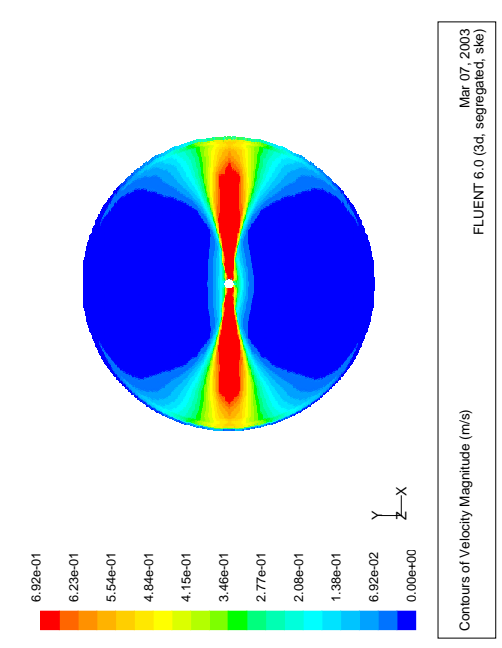

(40 in tank level)

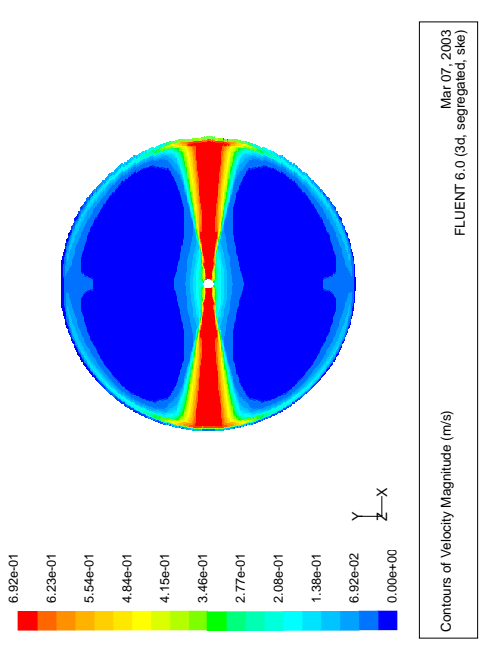

(65 in tank level)

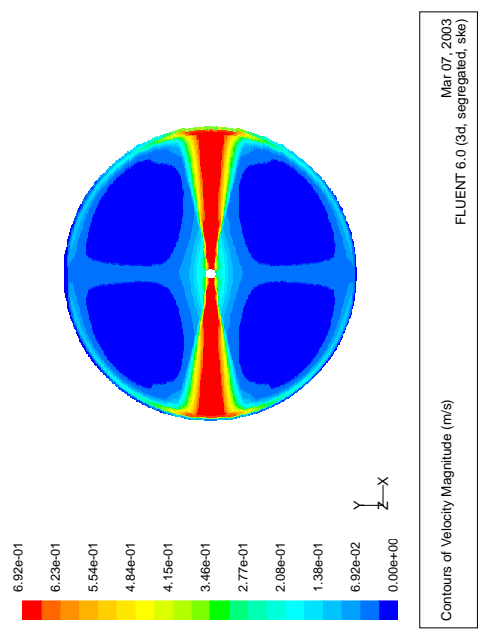

(90 in tank level)

Figure 18. Comparison of velocity distributions for various tank liquid levels at the pump discharge plane of the 85-ft tank with the fixed ADMP operation of 23-in nozzle elevation from the tank bottom (showing red zone to be greater than local velocity of $2.27 \mathrm{ft} / \mathrm{sec}$ )

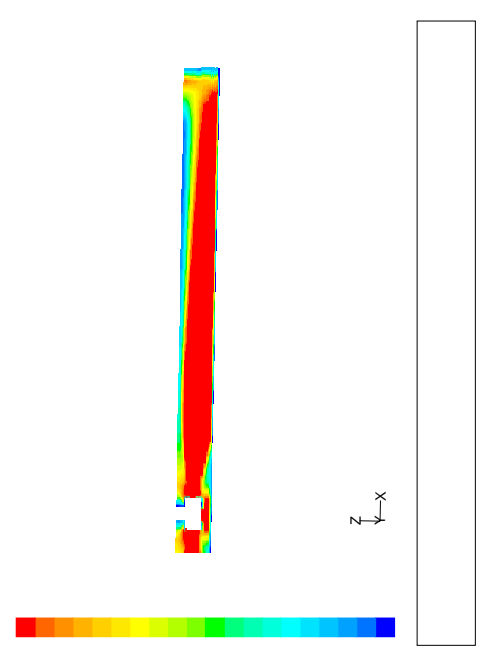

(40 in tank level)

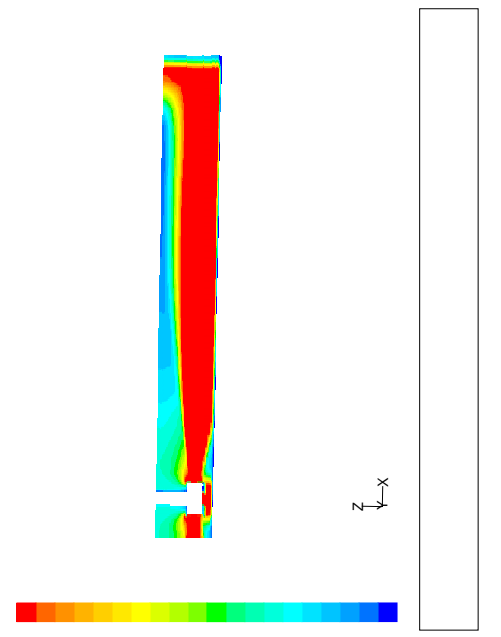

(65 in tank level)

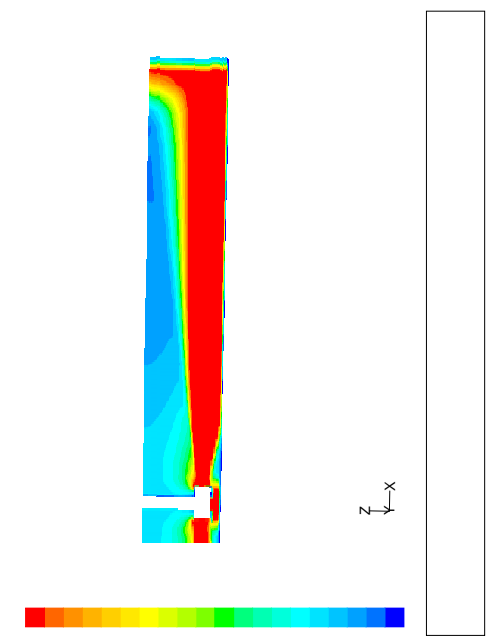

(90 in tank level)

Figure 19. Comparison of velocity distributions for various tank liquid levels at the vertical center-plane of the 85-ft tank with the fixed ADMP operation of 23-in nozzle elevation from the tank bottom (showing red zone to be greater than local velocity of $2.27 \mathrm{ft} / \mathrm{sec}$ ) 
Report: WSRC-TR-2003-00166

Date: $\quad 10 / 29 / 2003$

18
WESTINGHOUSE SAVANNAH RIVER COMPANY

EVALUATION OF SLUDGE REMOVAL CAPABILITIES FOR ADMP MIXER IN TANK

Page: $\quad 34$ of 48
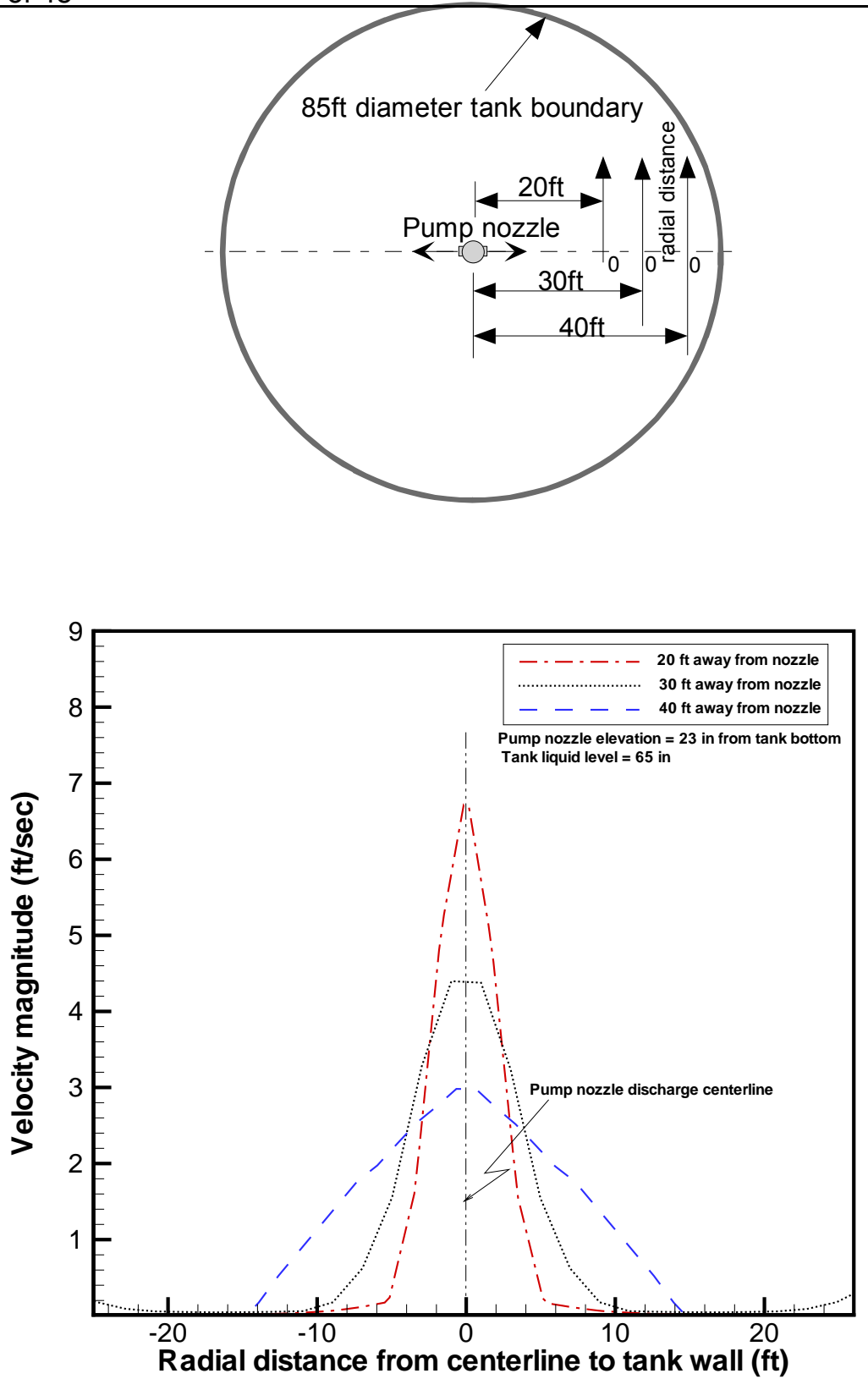

Figure 20. Comparison of velocity distributions along the pump discharge direction from pump nozzle to tank wall at the 23-in elevation of pump nozzle from the tank bottom 

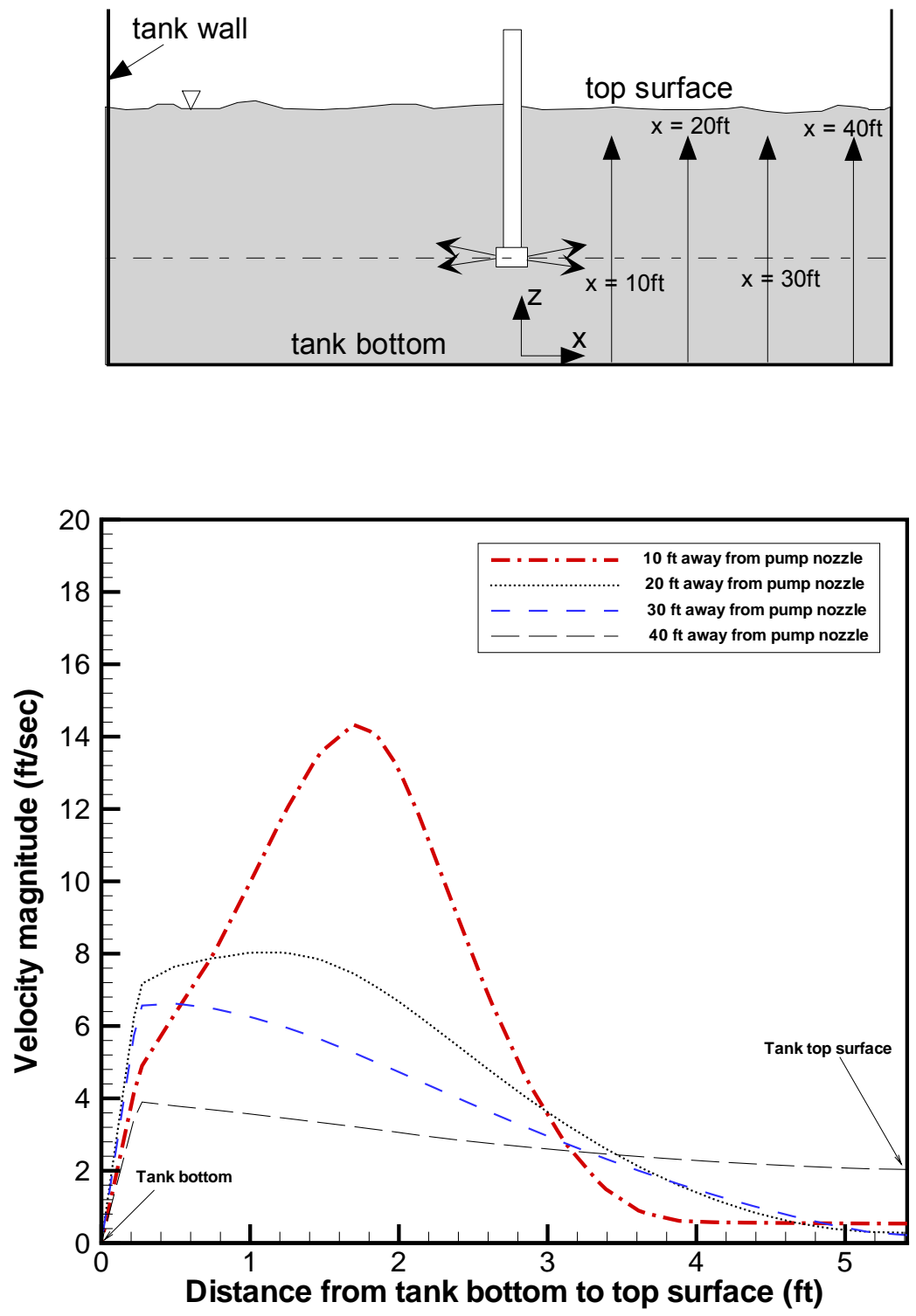

Figure 21. Comparison of velocity distributions along the vertical direction from tank bottom to top surface of tank at various distances from pump nozzle 
18

Page: $\quad 36$ of 48

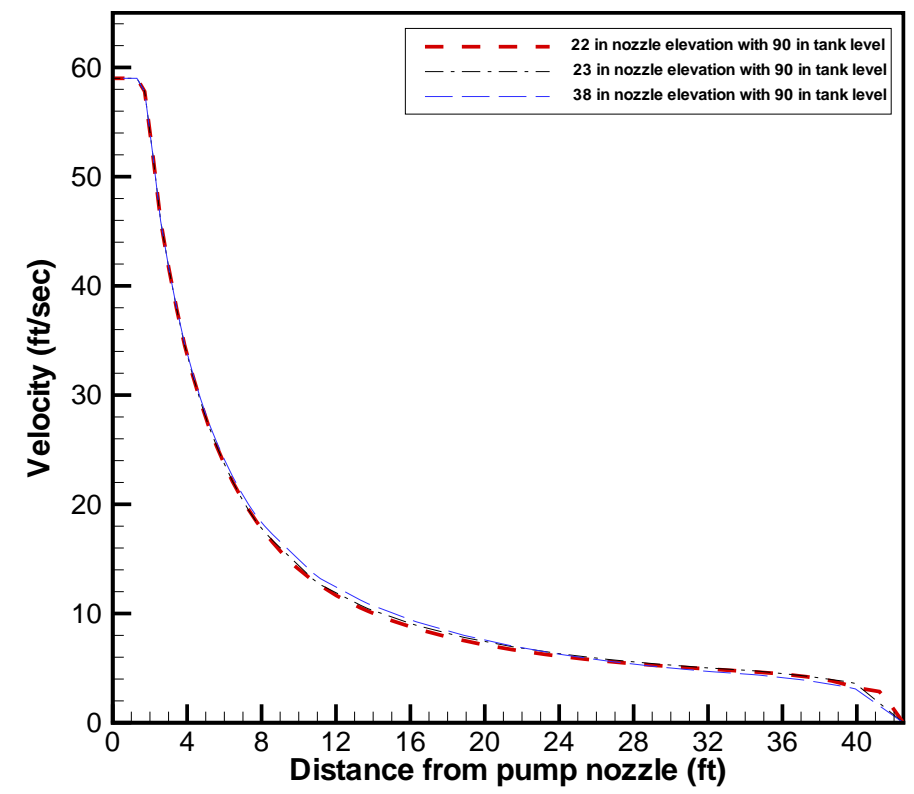

Figure 22. Comparison of velocity dissipations for various nozzle elevations with 90-in tank level along the pump discharge direction from pump nozzle to the tank wall at the elevation of each pump nozzle from the tank bottom

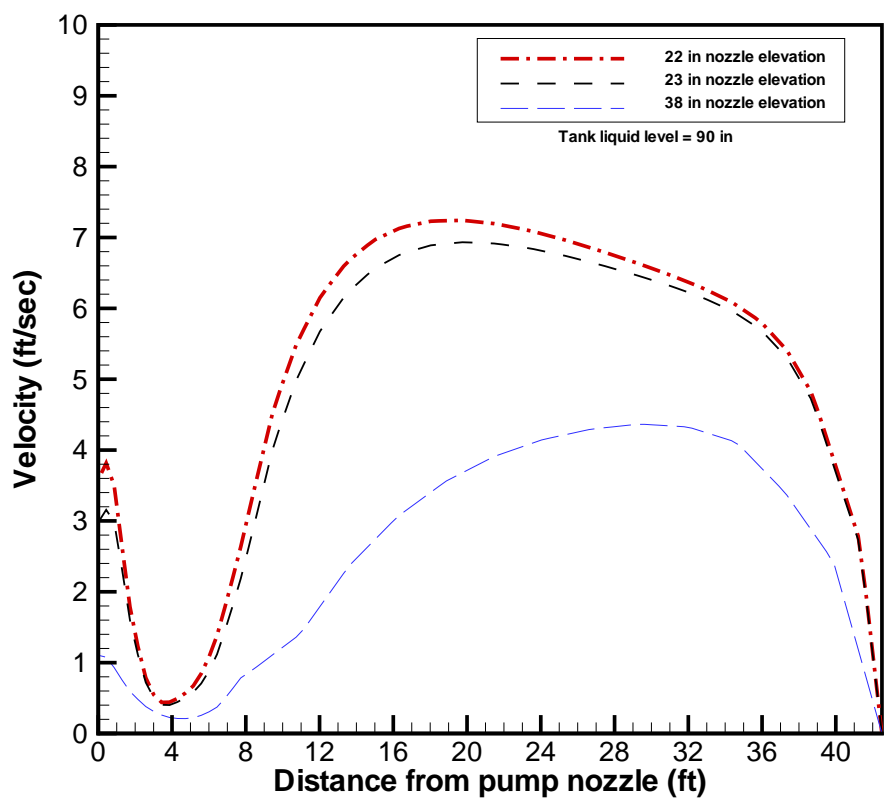

Figure 23. Comparison of local velocity magnitudes for various nozzle elevations with 90 -in tank level along the radial direction from pump nozzle to tank wall at 3in elevation from the tank bottom 


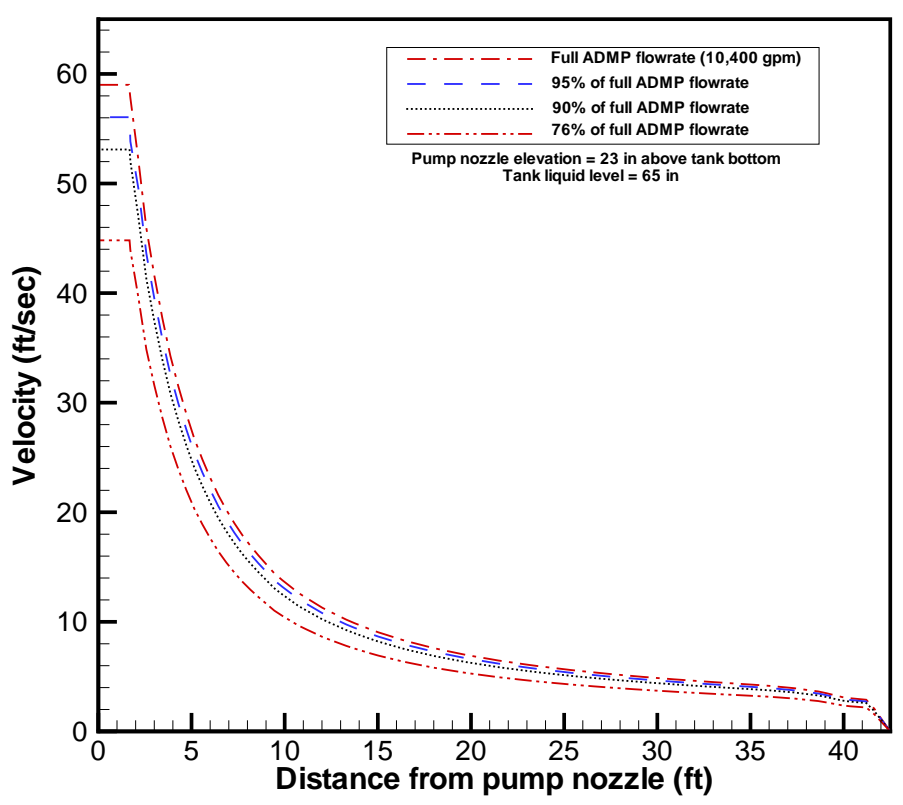

Figure 24. Comparison of velocity distributions for different inlet velocities along the pump discharge direction from pump nozzle to tank wall at the 23-in elevation of pump nozzle from the tank bottom under 65 in tank level

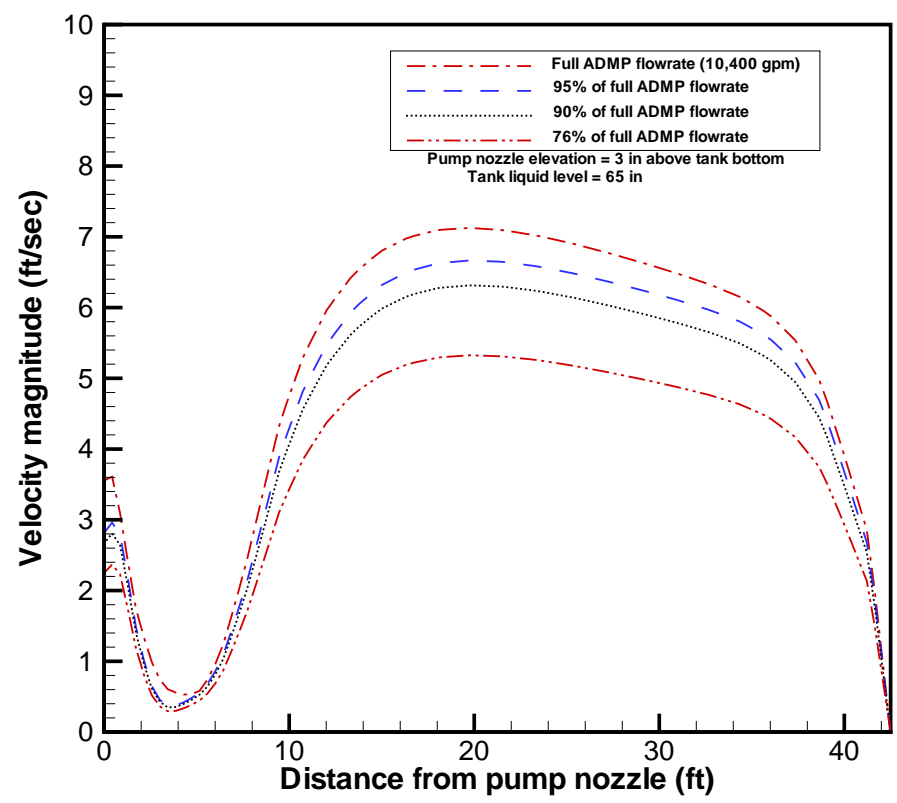

Figure 25. Comparison of velocity distributions for different inlet velocities along the pump discharge direction from pump nozzle to tank wall at 3 in elevation above the tank bottom under 65 in tank level 


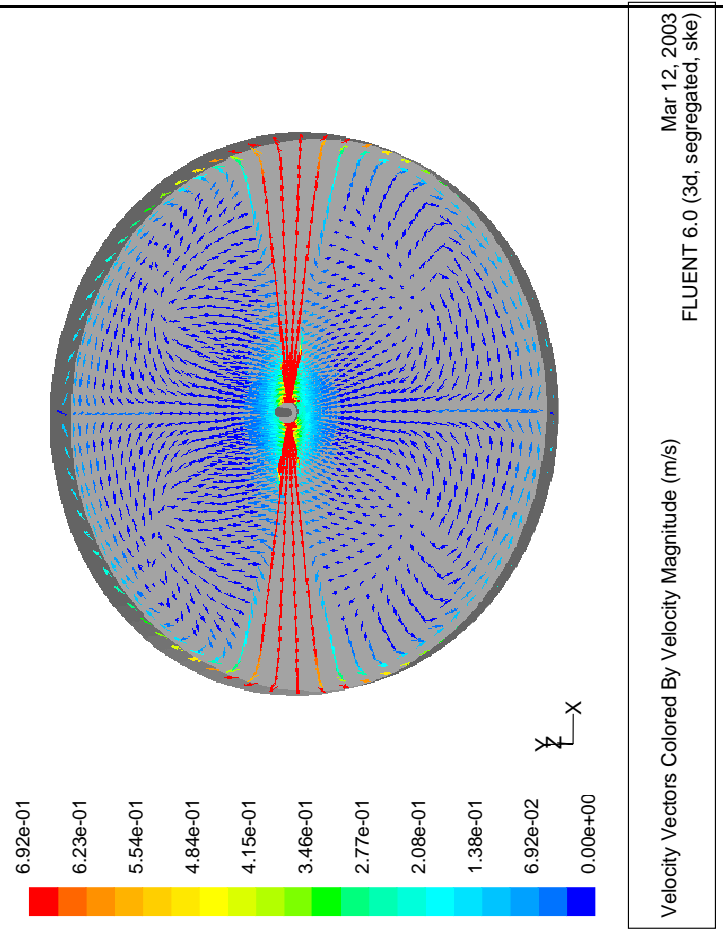

(Flow patterns for the model with no sludge mound)

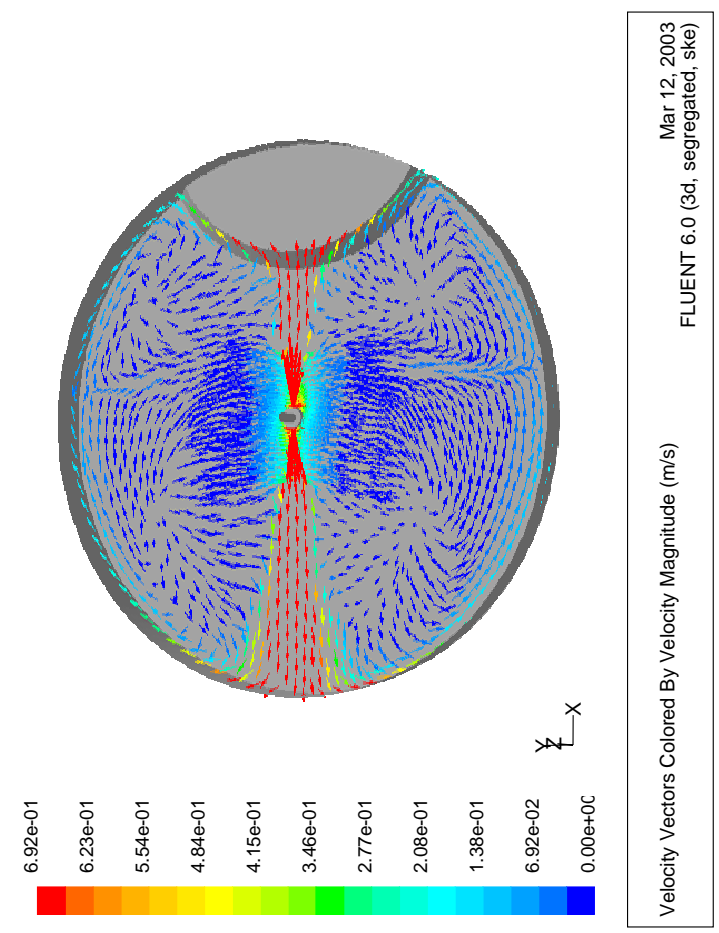

(Flow patterns for the model with sludge mound)

Figure 26. Comparison of flow patterns for Tank 18 with and without 26 -ft diameter and 23-in high sludge mound under fixed ADMP operation located at the center of the tank 


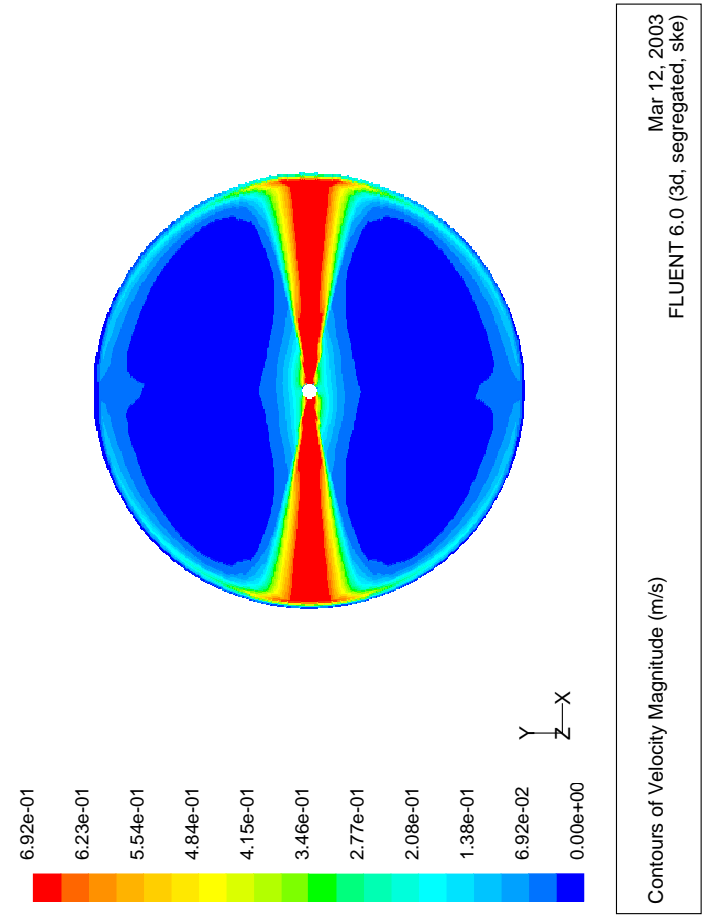

(Flow patterns for the model with no sludge mound)

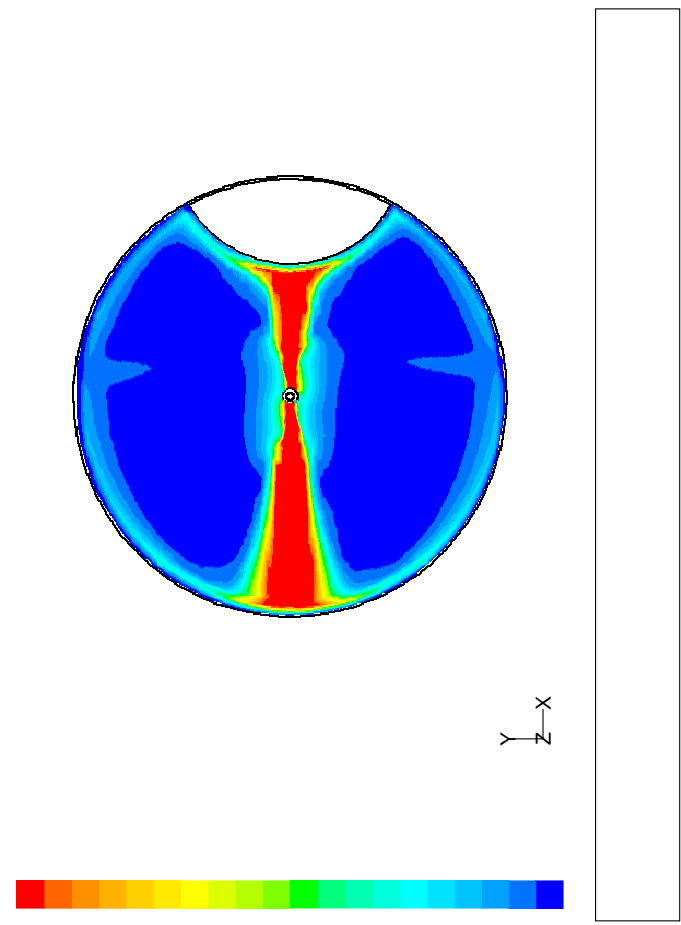

(Flow patterns for the model with no sludge mound)

Figure 27. Comparison of velocity contour plots for Tank 18 with and without $52-\mathrm{ft}$ diameter and 23-in high sludge mound at the discharge plane of pump nozzle under fixed ADMP operation located at the center of tank 


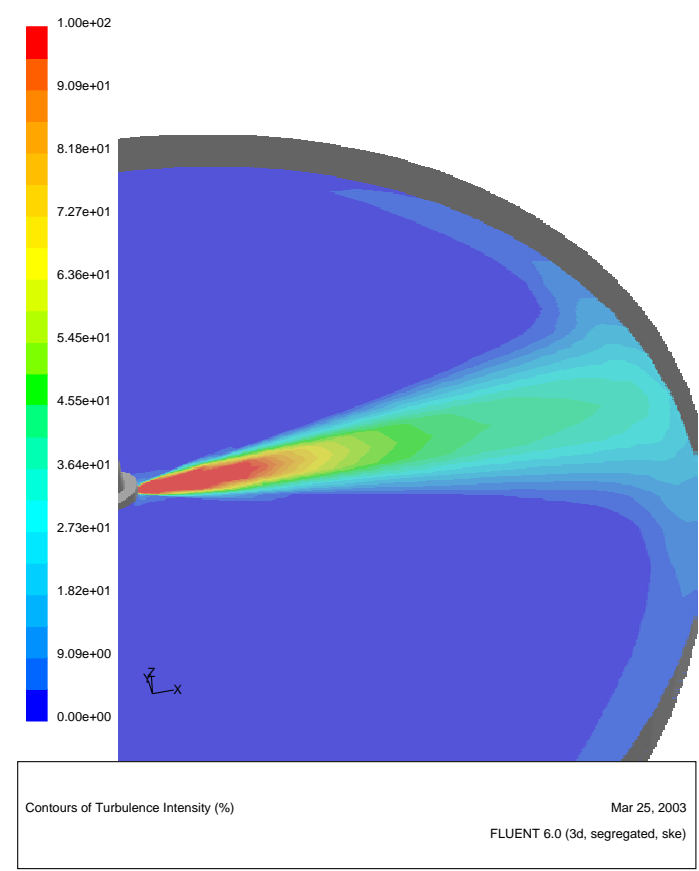

(Turbulence intensity for the model with no sludge mound)

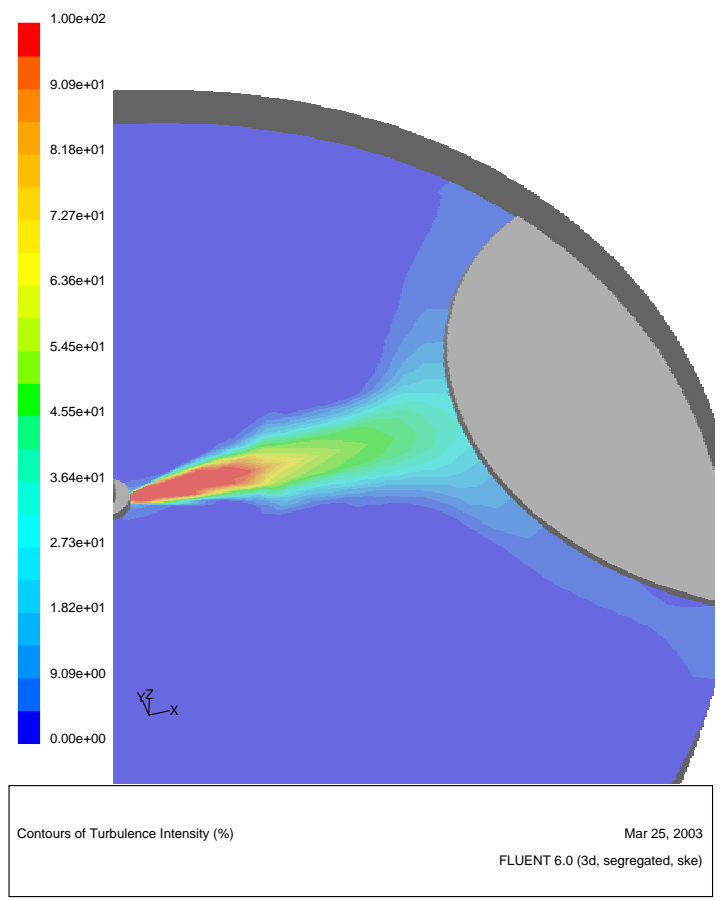

(Turbulence intensity for the model with sludge mound)

Figure 28. Comparison of turbulence intensities for Tank 18 with and without $52-\mathrm{ft}$ diameter and 23-in high sludge mound at the discharge plane of pump nozzle under fixed ADMP operation located at the center of tank 


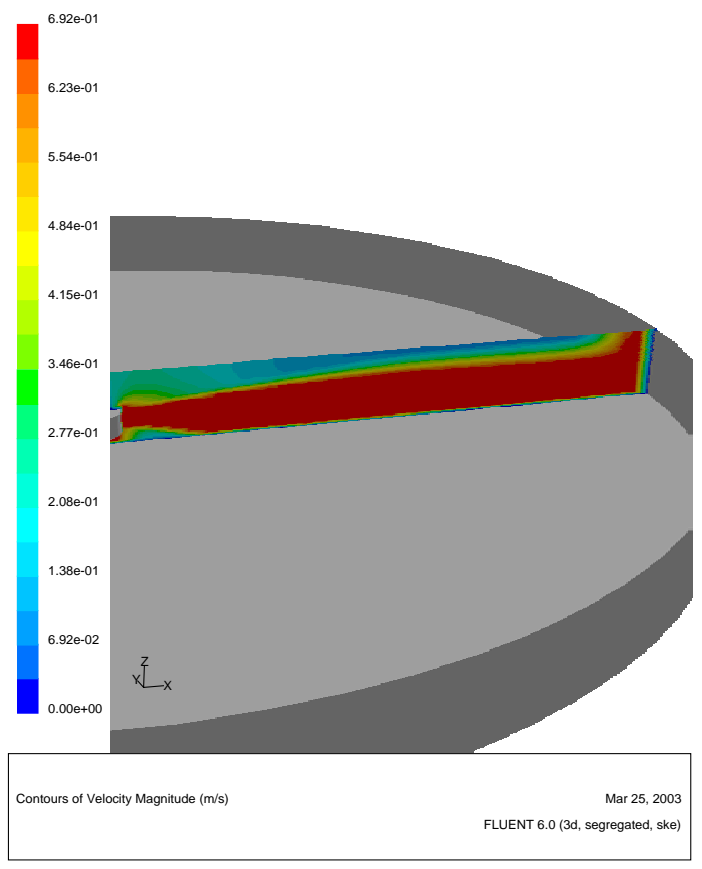

(Model with no sludge mound)

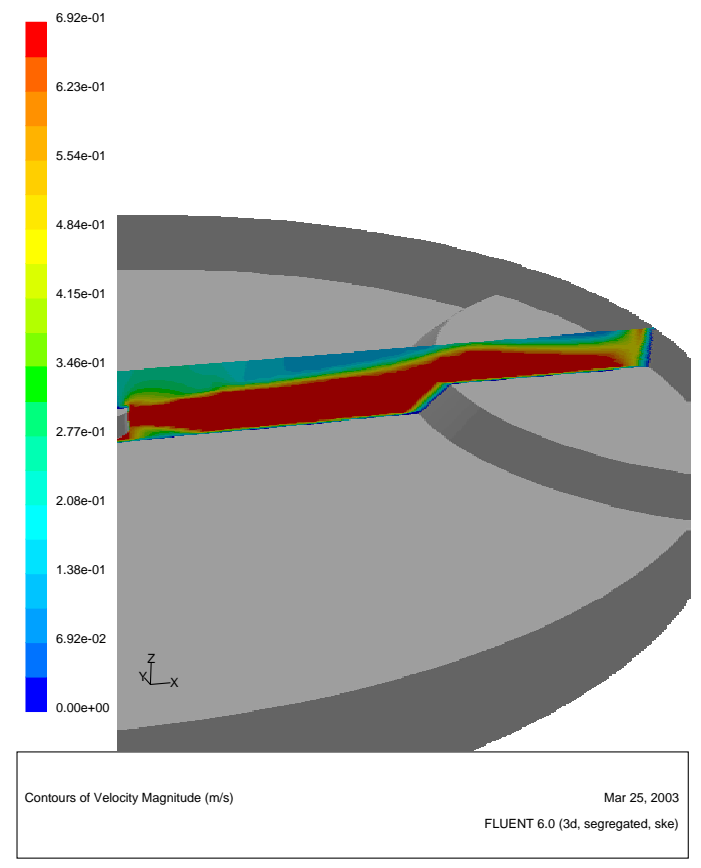

(Model with sludge mound)

Figure 29. Comparison of velocity contour plots for Tank 18 with and without 52-ft diameter and 23-in high sludge mound at the discharge plane of pump nozzle under fixed ADMP operation located at the center of tank

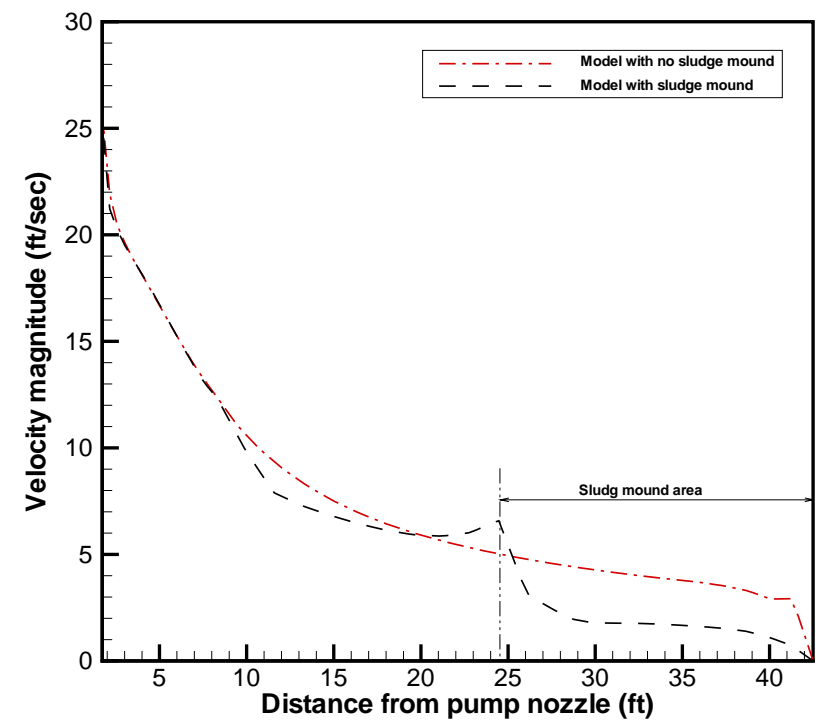

Figure 30. Comparison of velocity profiles at 1 in above pump nozzle for Tank 18 with and without 52-ft diameter and 23-in high sludge mound at the discharge plane of pump nozzle under fixed ADMP operation located at the center of tank 
Report: WSRC-TR-2003-00166

Date: $\quad 10 / 29 / 2003$ 18

Page: $\quad 42$ of 48

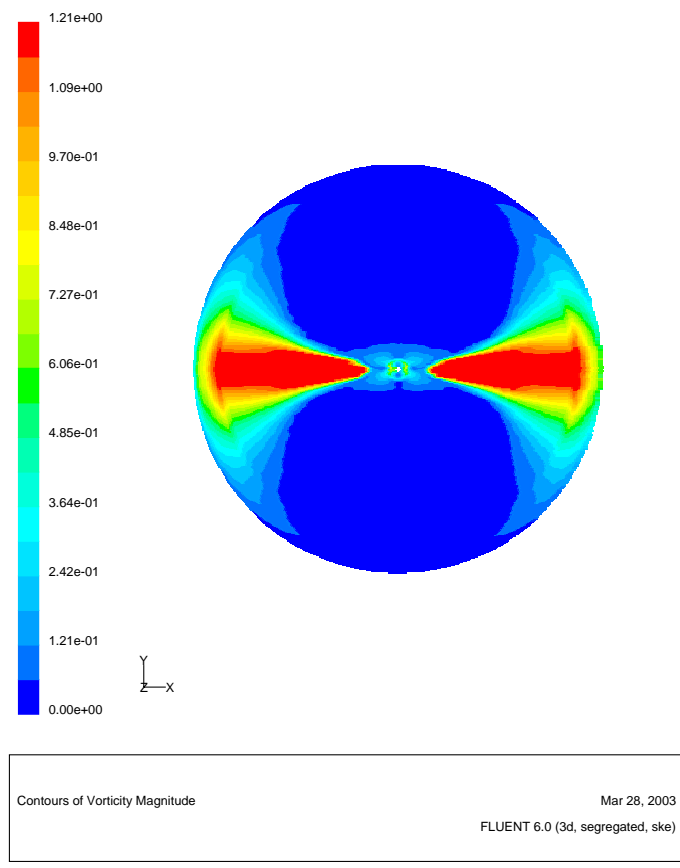

(40 in tank level for Tank 18)
WESTINGHOUSE SAVANNAH RIVER COMPANY

EVALUATION OF SLUDGE REMOVAL CAPABILITIES FOR ADMP MIXER IN TANK
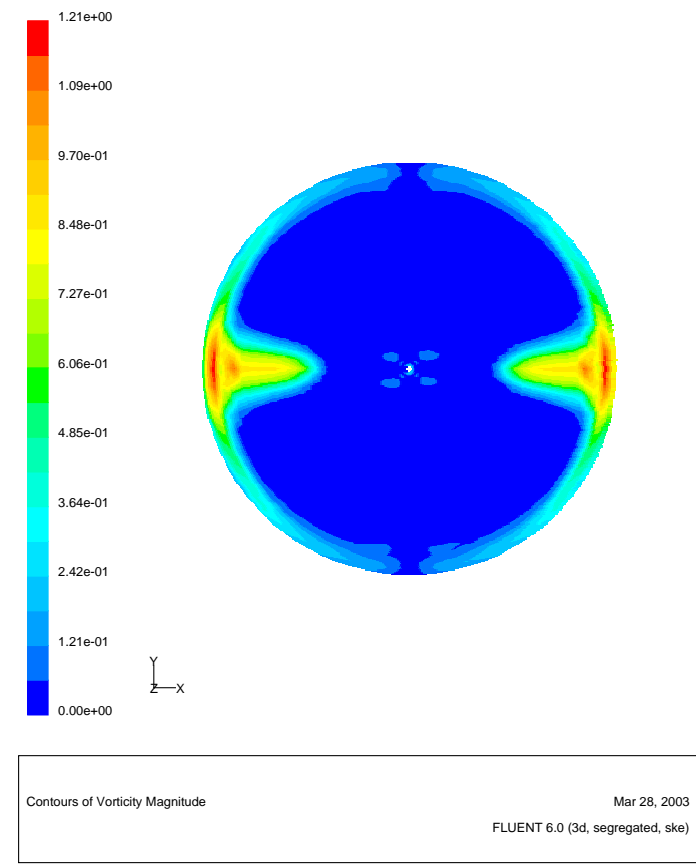

(65 in tank level for Tank 18)

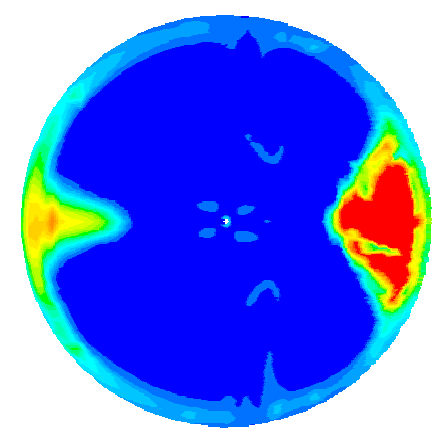

(65 in tank level for Tank 18 with sludge mound located at right-hand side)

Figure 31. Comparison of vorticity distributions at the top surface of tank for the Tank 18 models with and without sludge mound 


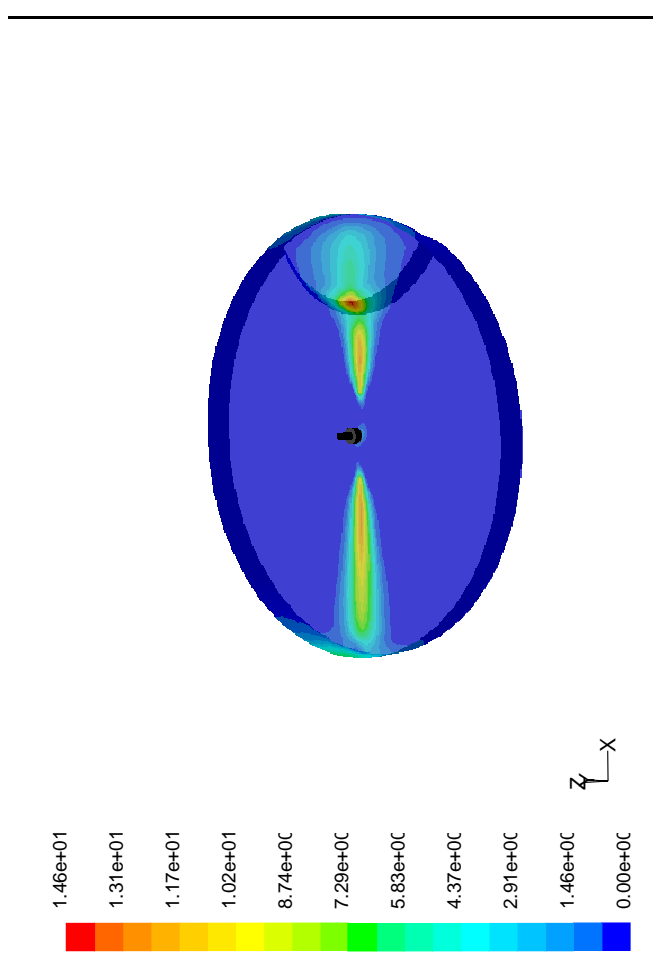

(Wall shear stress distributions on the tank wall and bottom floor)

Figure 32. Wall shear distributions around the wall of the 85-ft tank for Tank 18 with 45$\mathrm{ft}$ wide and 23-in high sludge mound under fixed ADMP operation located at the center of the tank

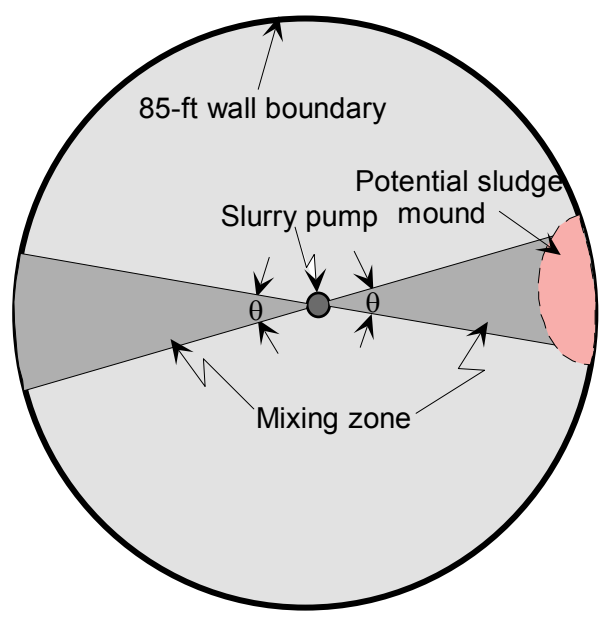

Figure 33. Mixing zone due to the flow evolutions of ADMP jet flow along the discharge direction with $\theta \approx 14^{\circ}$ spread angle 
Report: WSRC-TR-2003-00166

Date: $\quad 10 / 29 / 2003$

18

Page: $\quad 44$ of 48
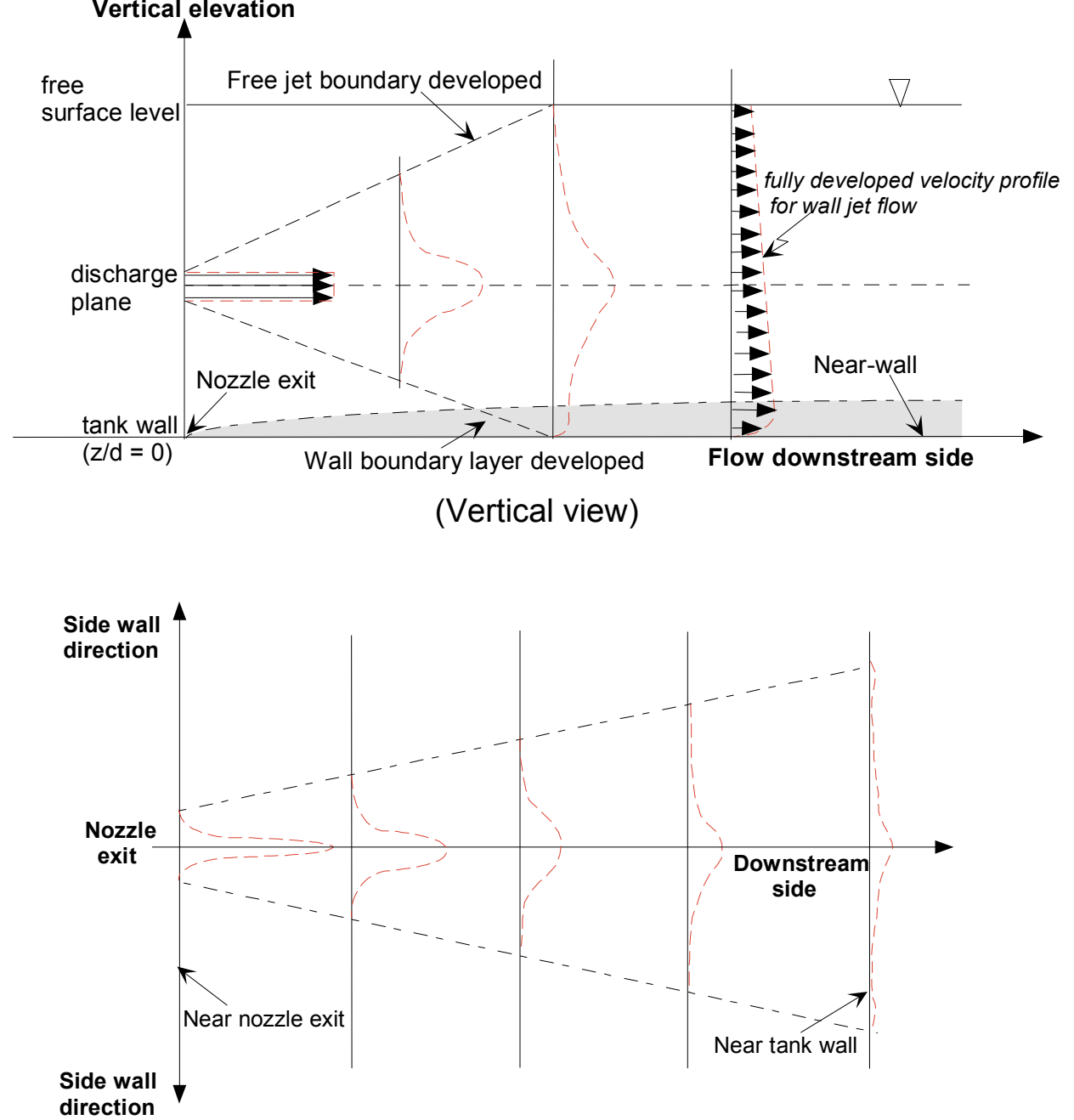

(Top view)

Figure 34. Qualitative velocity profiles in the direction perpendicular and parallel to the free surface from the modeling results of Tank 18 mixing simulations. 


\section{Summary and Conclusions}

Tank 18 simulation models with ADMP mixer submerged at the center of the tank have been developed to evaluate flow patterns induced by the mixer under potential operating conditions and to estimate the sludge suspension and cleaning capabilities using the velocity criteria established in the work. Calculations have been performed to assess the efficiency of sludge suspension and removal operations in Tank 18 during steadystate operations. Reference design and operating conditions were used as shown in Table 4. Solid obstructions including the pump housing, the 16" riser, and cohesive sludge mound were considered in the analysis, but free surface motion of the tank liquid was neglected since the liquid levels considered here are high enough to avoid highly wavy surface motion. The primary goal of the Tank 18 models is to estimate the maximum clearing capabilities of the ADMP mixer from a fixed pump for potential operational conditions.

A three-dimensional analysis with a two-equation turbulence model was performed with FLUENT $^{\mathrm{TM}}$, a commercial computational fluid dynamics (CFD) code since the basic model was validated with TNX test and literature data in the previous work [Ref. 2]. For a minimum suspension velocity of $2.27 \mathrm{ft} / \mathrm{sec}$, the results demonstrated that the existing ADMP mixer would provide adequate sludge removal from the tank with a 65 in liquid level except for a wall boundary of about $1 \mathrm{ft}$. In this case, if sludge particles are free and smaller than about 10 microns in diameter, fluid velocities adjacent to the wall region are high enough to keep them suspended. Sensitivity studies of different pump elevations and tank levels on the sludge suspension and removal capabilities were also performed assuming that local fluid velocity can be used as a measure of slurrying and mixing efficiency.

The main conclusions are as follows:

- The CFD simulation results show that higher tank level and lower pump elevation provide better cleaning capabilities with respect to the reference conditions, which are $5200 \mathrm{gpm}$ flowrate per nozzle under 23 in pump elevation and 65 in tank level.

- The results indicate that local velocities adjacent to the tank wall are potentially lower than those needed to remove some cohesive sludge materials. However, these velocities are high enough to keep particles picked up and swept aside if the solid particles are smaller than about 10 microns (larger than clay) and loosely packed on the floor.

- The calculation results show that about 2 days' pump operation with an indexed pump orientation aiming at the sludge mound is required to suspend cohesive materials assuming the material characteristics of Tank 18 sludge are similar to that of Tank 16 sludge.

All of this information will be used in decision making for the Tank 18 operating plan for waste removal with ADMP mixer located at the center of the tank. The information will also assist in identifying special requirements for sampling and monitoring the sludge suspension. 
Report: WSRC-TR-2003-00166

Date: $\quad$ 10/29/2003

18

Page:

46 of 48
WESTINGHOUSE SAVANNAH RIVER COMPANY

EVALUATION OF SLUDGE REMOVAL CAPABILITIES FOR ADMP MIXER IN TANK

(This Page Intentionally Left Blank) 


\section{References}

1. M. Hubbard, e-mail on TTR Input for Tank 18 CFD”, February 26, 2003.

2. S. Y. Lee and R. A. Dimenna, "Performance Analysis for Mixing Pumps in Tank 18", WSRC-TR-2001-00391 (October 2001).

3. G. Tatterson, "Sludge Suspension in Waste Storage Tanks", DPST-89-257, January 6, 1989.

4. N. V. Chadrasekhara Swamy and P. Bandyopadhyay, "Mean and Turbulence Characteristics of Three-Dimensional Wall Jets", Journal of Fluid Mechanics, Vol. 71, Part 3, pp. 541-562 (1975).

5. FLUENT, Fluent, Inc. (1998).

6. F. A. Zenz and D. F. Othmer, Fluidization and Fluid-Particle Systems, Chapter 6, Reinhold Publishing Corppration, New York (1960).

7. C. K. Madina and L. P. Bernal of F, "Interaction of a Turbulent Round Jet with the Free surface”, Journal of Fluid Mechanics, Vol. 261, pp. 305-332 (1994)

8. Personal Communications with M. Hubbard, March 10, 2003, and E-mail on Tank 18 ADMP Operations sent by M. Hubbard, April 8, 2003.

9. Abramovich, G. N., "The Theory of Turbulent Jets", The MIT Press, Cambridge, MA, 1963.

10. H. Schlichting, Boundary Layer Theory, McGraw-Hill Book Company, New York (1967).

11. W. H. Graf, Hydraulics of Sediment Transport, McGraw-Hill Book Company (1971).

12. W. M. Rohsenow and H. Y. Choi, Heat, Mass, and Momentum Transfer, PrenticeHall, Inc., New Jersey (1961).

13. H. Tennekes and J. L. Lumley, A First Course in Turbulence, The MIT Press, Cambridge, MA, 1972.

14. J. M. Dallavalle, Micromeritics, $2^{\text {nd }}$ Edition, Pitman Publishing Corporation, New York (1948).

15. G. Tatterson, "Jet Mixing in In-Tank Processing (U)", DPST-89-380", DPST-89380, January 24, 1989.

16. J. H. Perry, Chemical Engineers' Handbook, Fourth Edition, McGraw-Hill Book Co, New York.

17. E. J. Freed and O. S. Mukherjee, "Tank 8 Waste Removal Operating Plan", UESR-F-00009, Rev. 5, April 3, 2001.

18. R. G. Folsome and C. K. Ferguson, "Jet Mixing of Two Liquids", Transactions ASME, vol. 71, pp.73, 1949. 
Report: WSRC-TR-2003-00166

Date: $\quad$ 10/29/2003

18

Page:

48 of 48
WESTINGHOUSE SAVANNAH RIVER COMPANY

EVALUATION OF SLUDGE REMOVAL CAPABILITIES FOR ADMP MIXER IN TANK

(This Page Intentionally Left Blank) 